\title{
Vectofusin-1 Improves Transduction of Primary Human Cells with Diverse Retroviral and Lentiviral Pseudotypes, Enabling Robust, Automated Closed-System Manufacturing
}

\author{
Constanze Radek, ${ }^{1}$ Ornellie Bernadin, ${ }^{2-4}$ Katharina Drechsel, ${ }^{1}$ Nicole Cordes, ${ }^{1,5}$ Rita Pfeifer, \\ Pia Sträßer, ${ }^{1}$ Mirella Mormin, ${ }^{6}$ Alejandra Gutierrez-Guerrero, ${ }^{2-4}$ François-loïc Cosset, ${ }^{2-4}$ \\ Andrew D. Kaiser, Thomas Schaser, Anne Galy, ${ }^{6}$ Els Verhoeyen, ${ }^{2-4,7^{3}}$ and Ian C.D. Johnston ${ }^{1, *}$ \\ ${ }^{1}$ Miltenyi Biotec B.V. \& Co. KG, Bergisch Gladbach, Germany; ${ }^{2}$ CIRI-International Center for Infectiology Research, Team EVIR, Université de Lyon, Lyon, France; \\ ${ }^{3}$ Inserm, U1111, Ecole Normale Supérieure de Lyon, Lyon, France; ${ }^{4}$ Université Lyon 1, CNRS, UMR5308, Lyon, France; ${ }^{5}$ Faculty of Biology, University of Freiburg, \\ Freiburg, Germany; ${ }^{6}$ Integrare Research Unit UMR_S951, Genethon, INSERM, University Evry, EPHE, Evry, France; ${ }^{7}$ Université Côte d'Azur, INSERM, Centre \\ Méditerranéen de Médecine Moléculaire (C3M), Nice, France.
}

Cell and gene therapies are finally becoming viable patient treatment options, with both $\mathrm{T}$ cell- and hematopoietic stem cell (HSC)-based therapies being approved to market in Europe. However, these therapies, which involve the use of viral vector to modify the target cells, are expensive and there is an urgent need to reduce manufacturing costs. One major cost factor is the viral vector production itself, therefore improving the gene modification efficiency could significantly reduce the amount of vector required per patient. This study describes the use of a transduction enhancing peptide, Vectofusin- $1^{\circledR}$, to improve the transduction efficiency of primary target cells using lentiviral and gammaretroviral vectors ( $\mathrm{LV}$ and RV) pseudotyped with a variety of envelope proteins. Using Vectofusin-1 in combination with LV pseudotyped with viral glycoproteins derived from baboon endogenous retrovirus, feline endogenous virus (RD114), and measles virus (MV), a strongly improved transduction of HSCs, B cells and T cells, even when cultivated under low stimulation conditions, could be observed. The formation of Vectofusin-1 complexes with MV-LV retargeted to CD20 did not alter the selectivity in mixed cell culture populations, emphasizing the precision of this targeting technology. Functional, ErbB2-specific chimeric antigen receptor-expressing $\mathrm{T}$ cells could be generated using a gibbon ape leukemia virus (GALV)-pseudotyped RV. Using a variety of viral vectors and target cells, Vectofusin-1 performed in a comparable manner to the traditionally used surface-bound recombinant fibronectin. As Vectofusin-1 is a soluble peptide, it was possible to easily transfer the $\mathrm{T}$ cell transduction method to an automated closed manufacturing platform, where proof of concept studies demonstrated efficient genetic modification of T cells with GALV-RV and RD114-RV and the subsequent expansion of mainly central memory $\mathrm{T}$ cells to a clinically relevant dose.

Keywords: transduction, pseudotyping, CD34, CliniMACS Prodigy, automated manufacturing, immunotherapy

\section{INTRODUCTION}

CELL AND GENE therapy is entering a renaissance with successful therapies receiving market approval for use in oncological and stem cell transplantation settings. The current gold standard for the ex vivo genetic modification of target cells for these approaches is to use retroviral vector-based gene transfer technologies. ${ }^{1,2}$ To enable successful acceptance of these technologies into clinical routine, manufacturing must be simplified and costs must be reduced. ${ }^{3,4}$ One of the costlier reagents required for the manufacturing is the viral vector, therefore possible savings could be reached by reducing the viral vector production costs or by

${ }^{*}$ Correspondence: Dr. lan C.D. Johnston, Research and Development, Miltenyi Biotec B.V. \& Co. KG, Friedrich-Ebert-Strasse 68, Bergisch Gladbach 51429, Germany. E-mail. ianj@miltenyibiotec.de

(c) Constanze Radek et al., 2019; Published by Mary Ann Liebert, Inc. This Open Access article is distributed under the terms of the Creative Commons Attribution Noncommercial License (http://creativecommons.org/licenses/by-nc/4.0/) which permits any noncommercial use, distribution, and reproduction in any medium, provided the original author(s) and the source are cited. 
increasing the efficiency of viral vector transduction of target cells, thereby reducing the amount of viral vector required.

Modification of target cells with retroviral vectors often requires the presence of a transductionenhancing reagent. Polycationic reagents such as lipids, ${ }^{5}$ polymers, and peptides ${ }^{6}$ induce aggregation of vector particles and facilitate binding to target cells via modulation of electrostatic interactions, ${ }^{7}$ poloxamers influence membrane fluidity and improve transmembrane transport ${ }^{8}$ whereas bridging molecules, such as recombinant fibronectin, ${ }^{9}$ interact with both vector particle and cell membrane. These methods can also be combined with physical methods such as centrifugation, ${ }^{10}$ filtration, ${ }^{11}$ or magnetic force ${ }^{12,13}$ to further enhance transduction performance.

Rather than influencing vector cell surface binding and entry, alternative substances can also be used to modulate hematopoietic stem cell (HSC) physiology to increase the proportion of genetically modified cells. Rapamycin influences endocytotic mechanisms, ${ }^{14}$ staurosporine inhibits threonine/ serine kinases, which relax chromatin, and leads to an improved nuclear localization of the preintegration complex, ${ }^{15}$ while substances that improve HSC self-renewal and engraftment such as prostaglandin E2 and valproic acid also lead to increased HSC transduction rates. ${ }^{16,17}$

Effective transduction is also highly dependent on the pseudotyping protein used and the receptor availability on the target cell. ${ }^{18,19}$ For example, vesicular stomatitis virus G protein (VSVG)-pseudotyped lentiviral vectors $(\mathrm{LV})$ transduce primary T cells effectively at a low multiplicity of infection $(\mathrm{MOI}=1),{ }^{20}$ while HSCs often require 100 -fold more vector. ${ }^{21}$

To overcome restrictions in viral vector entry to HSCs, alternative pseudotypes have been developed, which also show reduced toxicity during production. $^{22,23} \mathrm{LV}$ pseudotyped with certain of these envelope proteins (e.g., feline endogenous leukemia retrovirus [RD114], gibbon ape leukemia virus [GALV], baboon endogenous retrovirus [BaEV]) require an enhancement reagent to effectively bind and enter $\mathrm{HSCs}^{22,24}$ and other cells such as T cells, while measles virus (MV)-LV pseudotyped with measles $\mathrm{H}$ and $\mathrm{F}$ glycoproteins achieve good transduction rates also in the absence of enhancers. However, MV-LV transduction of HSCs is also improved in the presence of transduction-facilitating agents such as retronectin, especially when the target cells are not stimulated by cytokines. ${ }^{25}$

In addition to HSC, these alternative pseudotypes are showing great promise in enabling viral modification of other difficult to transduce target cells such as B cells, ${ }^{26,27}$ resting or minimally stimulated $\mathrm{B}$ and $\mathrm{T}$ cells, ${ }^{28}$ and HSCs. ${ }^{24}$ An additional development is the modification of the natural viral envelope proteins to allow such pseudotyped lentiviruses to target any ligand of choice via fusion of binding domains such as singlechain antibodies $^{29,30}$ or DARPins ${ }^{31}$ to the MV H glycoprotein or the Nipah virus envelope glycoprotein G. ${ }^{32,33}$ These new pseudotypes enable highly selective targeting of specific cell types.

We have assessed Vectofusin- ${ }^{\circledR}$, a histidinerich, cationic amphipathic peptide, as an alternative transduction enhancer to modify primary $\mathrm{T}$ cells, B cells, and HSCs. Vectofusin-1 is a short amphipathic peptide of 26 amino acids, which can easily be synthesized to high purity for clinical use. It is a derivate of a group of antibiotic peptides (LAH4), which have also been shown to promote transfection of nucleic acids. ${ }^{34}$

Vectofusin-1 enhances the transduction of HSC with LV and gammaretroviral vectors (RV) pseudotyped with various envelope glycoproteins such as GALV-TR, RD-114, or Amphotropic envelopes, as well as with VSVG. ${ }^{35-37}$ Vectofusin- 1 acts at the entry step by promoting the adhesion and the fusion between viral and cellular membranes ${ }^{38}$ and also pulls down the particles toward the target cells by forming alpha-helical nanofibrils, which are required for the transduction-enhancing effects. ${ }^{39}$ Unlike recombinant fibronectin, it is a soluble reagent that does not have to be precoated on cell culture surfaces before use.

In this study, we show that Vectofusin-1 enhances transduction with RV and LV displaying a number of pseudotypes in T cells, B cells, and HSCs. In agreement with recent data from Jamali et al., ${ }^{40}$ the receptor specificity is maintained when using ligand-targeted envelopes, and we demonstrate that this reagent can be implemented in an automated and closed system for the manufacture of genetically modified T cells with RV at clinical scale. The robust performance with minimal manual interactions offers the perspective of reducing manufacturing costs for these exciting new therapies and therefore improving their accessibility to many patients in need of these novel medicinal products.

\section{MATERIALS AND METHODS \\ Primary cells and cell lines}

Fresh buffy coat, nonmobilized leukapheresis, adult peripheral blood, and umbilical cord blood were collected after informed consent from healthy donors according to the Declaration of Helsinki and was approved by the ethical committees of the 
University Hospital in Cologne, Germany (permit number: 03-055), the University Hospital in Ulm, Germany (permit number: 172/99), or by the French ministry of research in the case of blood samples collected at the Centre Hospitalier Sud Francilien, Evry, France (declaration number DC-2018-3276) and EFS (Etablissement français du Sang) Blood Bank (permit number 19-0027). Blood was collected in containers containing the anticoagulant, citratephosphate-dextrose (Sigma-Aldrich, France). Peripheral blood mononuclear cells (PBMCs) were isolated from buffy coats or leukapheresis products by low-density centrifugation on Pancoll (PanBiotech, Aidenbach, Germany).

$\mathrm{CD} \mathrm{9}^{+} \mathrm{B}$ cells and $\mathrm{CD}^{+} \mathrm{T}$ cells were purified by negative selection using the B Cell Isolation Kit II or the Pan T Cell Isolation Kit, human and autoMACS Pro Separator, or a manual protocol (all from Miltenyi Biotec). In some experiments, $\mathrm{T}$ cells were enriched by CD4- and CD8-positive selection using CD4 and CD8 MicroBeads, human and LS columns according to the manufacturer's instructions (Miltenyi Biotec).

CD34 ${ }^{+}$HSCs were isolated from cord blood WBC by positive magnetic cell separation using the autoMACS pro Separator (Miltenyi Biotec) after staining the cells with the human CD34 ${ }^{+}$MicroBead Kit (Miltenyi Biotec).

293T, HT1080, and MCF-7 cells (American Type Culture Collection, Manassas, VA) and 293VecRD114-TKGFP and 293Vec-Galv-TKGFP (BioVec Pharma, Inc., Quebec, Canada) were cultured in Dulbecco's Modified Eagle Medium (DMEM) (Biochrom, Nuaillé, France) while Raji and SupT1 cells (American Type Culture Collection) were cultured in RPMI (Biochrom). Both media were supplemented with $2 \mathrm{mM}$ glutamine (Lonza, Basel, Switzerland) and 10\% fetal bovine serum (FCS) (Biochrom, Berlin, Germany). HT1080 cells stably expressing human CD20 (CD20-HT1080) ${ }^{29}$ were used for titration of CD20 targeting vectors.

\section{RV generation and titration}

293Vec-RD114-TKiGFP and 293Vec-GALVTKiGFP stable production cell lines (BioVec Pharma, Inc.) were seeded at $1 \times 10^{7}$ cells per $175 \mathrm{~T}$ flask, and the supernatant was collected when the cells reached confluency. The viral vector was clarified by centrifugation at $1,000 \mathrm{~g}$ for $5 \mathrm{~min}$ and stored at $-80^{\circ} \mathrm{C}$. For vector titration, HT1080 cells were seeded in 24 -well plates at $1.1 \times 10^{5}$ cells per well for $20 \mathrm{~h}$ before transduction. On the day of transduction, the cells were placed in fresh medium without supplements, and retroviral vector was diluted in DMEM containing $8 \mu \mathrm{g} / \mathrm{mL}$ poly- brene before addition to the cells. Transgene expression was assessed by flow cytometry using a MACSQuant Analyzer 10.

The PG13-4D5-D12 retroviral vector encoding an ErbB2-specific chimeric antigen receptor (CAR) was a kind gift of Richard Morgan (National Cancer Institute, National Institute of Health). The vector was titered on T cells for 2 days after T Cell TransAct activation. Twenty-four-well plates were coated with $10 \mu \mathrm{g} / \mathrm{mL}$ Retronectin ${ }^{\circledR}$ (Takara Bio, Japan) in $0.5 \mathrm{~mL}$ PBS overnight at $4^{\circ} \mathrm{C}$ followed by a 30 -min blocking step with $2 \mathrm{~mL} \mathrm{PBS} / 2 \%$ bovine serum albumin. After removal of the blocking solution, 0.5$1 \mathrm{~mL}$ of the retroviral vector supernatant was added and the plate spun at $2,000 \mathrm{~g}$ at $32^{\circ} \mathrm{C}$ for $2 \mathrm{~h}$. Supernatant was removed and $5 \times 10^{5}$ activated $\mathrm{T}$ cells were added in $1 \mathrm{~mL}$ TexMACS medium containing supplements and the plate spun for $10 \mathrm{~min}$ at $300 \mathrm{~g}$. After overnight culture, the cells were transferred to a fresh plate and cultured until analysis by flow cytometry using an ErbB2-Fc fusion protein (R\&D Systems, MN) and anti-human-IgG (Fc gammaspecific) PE (eBioscience, San Diego).

\section{LV generation and titration}

Self-inactivating HIV-1-derived vectors encoding green fluorescent protein (GFP) under the control of a spleen focus foamy virus promoter were generated by transfection of $293 \mathrm{~T}$ cells as described in detail elsewhere. ${ }^{24,25}$ Vectors encoding GFP under control of a human phosphoglycerate kinase-1 promoter were generated by calcium phosphate transfection of $293 \mathrm{~T}$ cells with packaging plasmid constructs with varied envelope plasmid amounts: 2.75-fold more BaEVTR-encoding plasmid was applied compared with VSV-G. In the case of BaEVTR vectors, only the first $24 \mathrm{~h}$ collection was used and concentrated at $50,000 \mathrm{~g}$ for $2 \mathrm{~h}$, at $12^{\circ} \mathrm{C}$, resuspended in $\mathrm{PBS}$, aliquoted, and stored at $-80^{\circ} \mathrm{C}$. Infectious genome titers (IG/mL) were determined on HCT116 cells using qPCR as described. ${ }^{41}$

Pseudotyped LV particles specific for CD20 were generated by transient transfection of $293 \mathrm{~T}$ cells in T175 flasks with $1.76 \mu \mathrm{g}$ of plasmid encoding the MV $\mathrm{H}$ protein (pCG-H- $\Delta 18-\alpha \mathrm{CD} 20), 5.06 \mu \mathrm{g}$ of plasmid encoding the MV F protein (pCG-Fc $\Delta 30),{ }^{42}$ $33.44 \mu \mathrm{g}$ of a packaging plasmid encoding gag/pol/ rev (pCMV-dR8.74), and a psi-positive transfer vector plasmid encoding GFP (pHR-SEW). The pseudotyped LV particles were harvested $48 \mathrm{~h}$ posttransfection. After clarification, the supernatant was concentrated by centrifugation at $3,450 \mathrm{~g}$ through a $20 \%$ sucrose (Sigma-Aldrich, Cat. No. $84097-250 \mathrm{~g}, 20 \% \mathrm{w} / \mathrm{v}$ in PBS) cushion for $24 \mathrm{~h}$ at $4^{\circ} \mathrm{C}$. The pelleted LV were resuspended in $250 \mu \mathrm{L}$ 
precooled DMEM, aliquoted, and stored at $-80^{\circ} \mathrm{C}$ for later use. Vector was titrated on HT1080-CD20 cells by serial dilution in DMEM, and the transduction efficiency was determined by flow cytometry. The ratio of GFP-positive cells, the dilution factor, and the volume of lentiviral applied was used to calculate the LV titer (i.e., transducing units per volume [TU/mL]).

\section{Transduction with Vectofusin-1}

Vectofusin-1 (Miltenyi Biotec) was used to enhance transduction according to the manufacturer's instructions. Vectofusin-1 was reconstituted in water at $1 \mathrm{mg} / \mathrm{mL}$ and either used immediately or alternatively stored frozen in aliquots at $-70^{\circ} \mathrm{C}$. The reconstituted peptide was diluted in medium without serum and added to an equal volume of viral vector, also diluted in medium, and incubated for $10 \mathrm{~min}$ to allow viral vector-Vectofusin-1 complexes to form. The mixture was then added to the target cells such that the end concentration of the peptide was 10 or $12 \mu \mathrm{g} / \mathrm{mL}$ in supplemented medium. The cells were then incubated overnight at $37^{\circ} \mathrm{C}$ or alternatively subjected to centrifugation at $400 \mathrm{~g}$ for $2 \mathrm{~h}$ at $32^{\circ} \mathrm{C}$ (spinoculation) before further cultivation at $37^{\circ} \mathrm{C}$. Medium was exchanged 18-24h after transduction.

\section{Cultivation and transduction of $B$ cells and IL-7-treated $T$ cells}

Freshly isolated unstimulated $\mathrm{T}$ and $\mathrm{B}$ lymphocytes were seeded in RPMI 1640 medium (Gibco Invitrogen, Auckland, New Zealand) supplemented with 10\% FSC (Lonza, Verviers, Belgium) and penicillin/streptomycin (Gibco, Invitrogen, Auckland, New Zealand). T cells were precultivated for 3 days with rIL-7 (20 ng/mL; BD Biosciences), while B cells were stimulated for $24 \mathrm{~h}$ with Pansorbin A (Sigma) and IL2 (100 ng/mL; Miltenyi Biotec) before transduction.

$5 \times 10^{4} \mathrm{~T}$ or B cells were seeded in 48 -well plates in $100 \mu \mathrm{L}$ of medium. The volume of concentrated vector for the indicated MOI was preincubated with Vectofusin-1 in serum-free Opti-MEM medium for $10 \mathrm{~min}$. After the incubation period, RPMI/10\% FCS medium was added to the mixture to reach a volume of $100 \mu \mathrm{L}$ and then added on the cells (final concentration Vectofusin $=12$ $\mu \mathrm{g} / \mathrm{mL}$ ). The cells were washed the next day and were replenished with fresh medium and cytokines every 3 days. Three and 6 days after transduction, the percentage of $\mathrm{GFP}^{+}$cells was determined by flow cytometry. Where indicated, transductions were performed on Retronectincoated plates according to the manufacturer's instructions (Takara Bio).

\section{Cultivation and transduction of TransAct-stimulated $T$ cells}

$T$ cells were resuspended at a density of $1 \times 10^{6}$ cells/mL in TexMACS medium containing human IL-2 (40 IU/mL) and stimulated with $\mathrm{T}$ Cell TransAct (all from Miltenyi Biotec). One day after activation, $\mathrm{T}$ cells were transduced with the respective vector in the presence or absence of Vectofusin-1. Cell numbers were determined every 2-3 days, and fresh TexMACS medium supplied with $40 \mathrm{IU} / \mathrm{mL}$ IL-2 was added to maintain a cell concentration of $1 \times 10^{6}$ cells $/ \mathrm{mL}$. In some experiments, T cells were stimulated in RPMI 1640 medium (Gibco Invitrogen) supplemented with $10 \%$ FCS (Lonza, Verviers, Belgium) and human IL-2 (20 ng/mL; BD Biosciences).

\section{Cultivation and transduction of $\mathrm{CD}^{+} 4^{+}$cells}

Human $\mathrm{CD} 34^{+}$cells were prestimulated for $24 \mathrm{~h}$ in StemMACS medium or HSC-Brew GMP medium (Miltenyi Biotec) supplemented with $2 \%$ human serum albumin (HSA) (Octapharma) and cytokines $(20 \mathrm{ng} / \mathrm{mL}$ TPO, $100 \mathrm{ng} / \mathrm{mL} \mathrm{SCF}$, $100 \mathrm{ng} / \mathrm{mL}$ Flt-3; Miltenyi Biotec). In some experiments, $60 \mathrm{ng} / \mathrm{mL}$ IL-3 (Miltenyi Biotec) was additionally present and X-VIVO 20 culture medium (Lonza, Basel, Switzerland) was used. Both vectors and Vectofusin-1 were diluted in serumfree medium (Opti-MEM; Life Technologies, or HSC-Brew GMP medium; Miltenyi Biotec). The diluted Vectofusin-1 $(24 \mu \mathrm{g} / \mathrm{mL})$ and diluted viral vector were mixed at a 1 to 1 volume (final concentration $12 \mu \mathrm{g} / \mathrm{mL}$ Vectofusin-1) and incubated for $10 \mathrm{~min}$. CD34 ${ }^{+}$cells were then incubated with this mixture for $24 \mathrm{~h}$. Cells were washed and were then resuspended in StemMACS or HSC-Brew GMP medium supplemented with cytokines.

In some experiments, X-VIVO 20 medium (Lonza, Levallois-Perret, France) supplemented with cytokines $(25 \mathrm{ng} / \mathrm{mL}$ h-TPO, $25 \mathrm{ng} / \mathrm{mL}$ h-SCF, $50 \mathrm{ng} / \mathrm{mL}$ h-Flt-3, and $10 \mathrm{ng} / \mathrm{mL}$ h-IL-3) were used. In these experiments, $6 \mathrm{~h}$ post-transduction, viral vectors and additives were washed out and cells were further cultivated in X-VIVO 20 medium, cytokines, and 10\% FCS albumin. Culture medium was refreshed by replacing half of the culture medium with fresh medium containing cytokines, every 2 days. After 6 days, viability and transduction efficiency were evaluated, respectively, by 7-AAD labeling and measurement of GFP expression using flow cytometry.

Transduction efficiency and cell viability were determined at day 4, 6, or 7 post-transduction. For vector copy number (VCN) measurements, 0.5$1 \times 10^{6}$ cells were used to extract DNA using the 
Promega Wizard genomic DNA kit (Promega, Madison) following the manufacturer's recommendations. Alternatively, transduced and control cells were plated in methylcellulose medium supplemented with human cytokines (Stem Cell Technologies, Grenoble, France) according to the manufacturer's instructions, and colonies were counted and characterized by microscopic analysis at day 14 .

\section{Conditioning and reconstitution of NOD/SCIDgammaC ${ }^{-/-}$mice}

NOD/SCIDgammaC ${ }^{-/-}$(NSG) mice were housed in our animal facility (PBES-Lyon, France). Experiments were performed in accordance with the EU guidelines upon approval of the protocols by the local ethical committee (Authorization agreement number C2EA -15: CECCAPP, Lyon, France).

Two- to 3-day-old newborn NSG mice were subjected to 1 Gy irradiation and $2 \times 10^{5}$ transduced, prestimulated cord blood CD34 ${ }^{+}$cells were injected intra-hepatically. After 12 weeks of reconstitution, extensive cell phenotyping in the different hematopoietic tissues (bone marrow [BM], spleen, thymus, blood) was performed by flow cytometry.

Total human cell engraftment in the BM, thymus, peripheral blood, and spleen was assessed by analysis of human and mouse CD45 expression (CD45-VioGreen, human, and CD45-VioBlue, mouse). Staining of human progenitors and the early B cell population in spleen and BM was performed using CD34-PE and CD19-APC. Thymic subpopulations were identified via CD3-PE, CD8VioGreen and CD4-APC immunostaining. All antibodies were from Miltenyi Biotec.

\section{MV-LV co-culture experiment}

SupT1 cells were stained with Violet Cell Trace (Thermo Fisher) according to the manufacturer's instructions using $1 \mu \mathrm{M}$ Violet Cell Trace. $1.5 \times 10^{5}$ SupT1 and $1.5 \times 10^{5}$ Raji cells were seeded together in a total volume of $100 \mu \mathrm{L} \mathrm{RPMI} / 2 \mathrm{mM}$ L-glutamine in a 48-well plate. Vectofusin-1 was diluted in $\mathrm{RPMI} / 2 \mathrm{mM}$ L-glutamine to a final concentration of $0.06 \mathrm{mg} / \mathrm{mL}$. The vector was diluted in RPMI/ $2 \mathrm{mM}$ L-glutamine. Equal volumes of diluted vector and Vectofusin-1 were mixed shortly before transduction $(\mathrm{MOI}=0.05)$, and $50 \mu \mathrm{L}$ of the transduction mix was added to the cells (total culture volume $150 \mu \mathrm{L})$. After $3 \mathrm{~h}$ at $37^{\circ} \mathrm{C}, 850 \mu \mathrm{L} \mathrm{RPMI} / 10 \% \mathrm{FCS} /$ $2 \mathrm{mM}$ L-glutamine was added. Transduction efficiency was analyzed 3 days post-transduction by flow cytometry (MACSQuant Analyzer 10; Mil- tenyi Biotec). Before analysis, the Raji cells were stained with an anti-CD20-PerCP antibody (Miltenyi Biotec).

\section{Automated GMP transduction}

The automated $\mathrm{T}$ cell transduction (TCT) process was performed on the CliniMACS Prodigy ${ }^{\mathrm{TM}}$ instrument in combination with the closed, singleuse TS520 tubing set. The TCT process for use with LV has been described in detail previously. ${ }^{43}$ Briefly, apheresis samples containing a maximum of $3 \times 10^{9}$ target cells were washed and magnetically labeled with CliniMACS CD4 Reagent and CliniMACS CD8 Reagent (Miltenyi Biotec) at 4$8^{\circ} \mathrm{C}$. T cells were magnetically enriched before being taken into culture in TexMACS GMP medium (Miltenyi Biotec) supplemented with 3\% heat-inactivated human $\mathrm{AB}$ serum (Gemini BioProducts; pooled from a maximum of 25 donors), $40 \mathrm{IU} / \mathrm{mL}$ of recombinant human IL-2 (Miltenyi Biotec).

The $\mathrm{T}$ cells were then activated with the contents of one vial $(4 \mathrm{~mL})$ of MACS GMP $\mathrm{T}$ Cell TransAct (Miltenyi Biotec) in final culture volume of $70 \mathrm{~mL}$ cells. T cells were transduced $48 \mathrm{~h}$ after $\mathrm{T}$ cell stimulation using retroviral vectors in the presence or absence of MACS GMP Vectofusin-1 (Miltenyi Biotec) according to the manufacturer's instructions. Vectofusin-1 was reconstituted in $1 \mathrm{~mL}$ water, diluted in nonsupplemented TexMACS GMP medium, and mixed with retroviral supernatant diluted in the same volume of medium in a bag. After 10 min incubation, the bag was welded to the tubing set and a spinoculation transduction performed at $400 \mathrm{~g}$ for $2 \mathrm{~h}$.

A culture wash was automatically performed 3 days after stimulation to remove excess stimulation reagent and viral vector, and the cells were subsequently maintained in agitated culture conditions in volumes increasing up to $250 \mathrm{~mL}$ over time with automated feeding steps. Automated media exchange via centrifugation was executed every day via replacement of a maximum of $180 \mathrm{~mL}$ of culture medium. After 6 days of cultivation, the media bag was exchanged. Formulation and harvest of cells were performed using isotonic sodium chloride solution (Baxter) supplemented with 0.5\% HSA (Grifols).

Cultivation samples were taken frequently. Cell count as well as viability were analyzed via hemocytometer and erythrosine B staining. The $\mathrm{pH}$ value of the culture samples was measured using $\mathrm{pH}$ test strips (MColorpHast, $\mathrm{pH}$ 6.5-10; Merck). Glucose concentration was measured using a handheld blood sugar meter (ACCU-CHECK, 
Aviva). For the enriched fraction (day 0), the inprocess control (day 7), and for the final cellular product (day 9 or 13), samples were taken for flow cytometric analysis to determine cellular composition, $\mathrm{T}$ cell phenotype, and transduction efficiency.

\section{VCN assay}

Average VCN per cell was measured in total genomic DNA (Promega Wizard genomic DNA kit) using qPCR, which consists of a duplex amplification of vector Psi sequence and cellular ALB gene sequences as already reported. ${ }^{44}$ Samples were measured in duplicate in four qPCR separate experiments, 7 days after transduction of cells.

\section{Flow cytometry}

MACSQuant Analyzer, MACSQuant Analyzer VYB (Miltenyi Biotec), or FACSCanto, LSRII (Becton Dickinson, NJ) was used to analyze cell populations by flow cytometry. The following antibody and protein conjugates were used: CD3-PE, CD3-APCVio770, CD4-APC, CD4-VioGreen, CD8-APC-Vio770, CD8-VioGreen, CD14-APC, CD16-PE, CD19-APC, CD20-PerCP-Vio770, CD20-PE-Vio770, CD34-APC, CD34-PE, CD45-VioBlue, CD45-VioGreen, CD45ROPE-Vio770, CD56-PE, CD62L-VioBlue, CD95-APC, CD45-VioBlue (mouse) (all from Miltenyi Biotec); ErbB2-Fc fusion protein (R\&D Systems), antihuman-IgG (Fc gamma-specific) PE (eBioscience). 7AAD staining was used for dead cell exclusion and Violet Cell Trace (Thermo Fisher) for SupT1 cell tracking.

\section{Cytokine secretion assay}

Cytokine secretion assays were conducted by coculturing CAR T cells with target cells at a ratio of 1:2 for $24 \mathrm{~h}$ in TexMACS medium (Miltenyi Biotec). Routinely, co-cultures were set up in U-bottomed 96well plates with $5 \times 10^{4}$ CAR-positive effector cells and a total volume of $200 \mu \mathrm{L}$. Harvested supernatants were either stored at $-20^{\circ} \mathrm{C}$ until further processing or analyzed directly using the MACSPlex Cytokine 12 Kit for human analytes (Miltenyi Biotec). Flow cytometric measurements and subsequent data analysis were performed automatically using the MACSQuant Express Mode for MACSPlex.

\section{Statistical analyses}

Statistical analyses were performed with Prism 7 software (GraphPad). Tests for statistical significance used the unpaired two-tailed Student's $t$-test or one-way ANOVA (Tukey's multiple comparisons test) as indicated; $p$-values less than 0.05 were considered significant.

\section{RESULTS}

Transduction efficiency of hCD34 cells with baboon- and measles-pseudotyped $L V$ is enhanced by Vectofusin-1

$\mathrm{LV}$ pseudotyped with the $\mathrm{BaEV}$ envelope protein (BaEV-LV) can only transduce CD34 ${ }^{+} \mathrm{HSC}$ with low efficiency in the absence of enhancement reagents (2-27\%; Fig. 1A, D), while VSVG-pseudotyped vectors (VSVG-LV) show good transduction performance at high MOI (38.4\%, Fig. 1G). ${ }^{45}$ When vector particles are pre-complexed with Vectofusin-1 before contact with the target cells, an efficient modification of $\mathrm{HSC}$ with BaEV-LV (up to 98.9\%; Fig. 1A, D, E, and G), also at low MOI and vector concentration, is possible, reaching similar proportions (88-89\%) of genetically modified cells compared to a recombinant fibronectin control (75-80\%; Fig. 1A). This efficient transduction performance is maintained across different manufacturing lots of the peptide (Fig. 1B) and has no effect on $\mathrm{CD}^{+} 4^{+} \mathrm{HSC}$ viability in culture or colony-forming potential (Fig. 1C, F).

There is a clear relationship between the vector dose used for transduction and the number of GFPexpressing CD34 cells and the integrated genome copies that can be detected in the modified CD34 ${ }^{+}$ cells (Fig. 1D, E). To confirm stable transduction of HSCs, CD34 $4^{+}$cells, modified in the presence of Vectofusin-1 with BaEV-LV and MV-LV encoding GFP, were transplanted into irradiated NSG mice. The level of reconstitution and gene marking was assessed in the different hematopoietic lineages in the thymus, spleen, and BM 12 weeks later by flow cytometry (Supplementary Fig. S1). In this experiment, a high level of gene marking ( $>90 \%$ ) was maintained long-term in vivo in $\mathrm{CD}^{+} 4^{+}$progenitors and $\mathrm{B}$ cells in the BM, T cells in the thymus, and B cells in the spleen indicating that true HSC (SCID repopulating cells) were transduced and maintained during the in vitro protocol.

\section{Vectofusin-1 augments LV transduction of $T$ cell receptor-stimulated human $T$ cells, $B$ cell receptor-stimulated $B$ cells, and also $T$ cells minimally stimulated with IL-7}

The use of VSVG-LV for transducing activated human $\mathrm{T}$ cells has been well documented. ${ }^{20,46} \mathrm{~T}$ cells activated by cross-linking of the T cell receptor (TCR) via anti-CD3 antibodies and with optional co-activation signals such as anti-CD28 can be efficiently modified with VSVG-LV (48.6\%; Fig. 2A). Likewise, MV-LV-pseudotyped vectors can transduce $\mathrm{T}$ cells effectively (58.2\%), while RD114-LV require an enhancement reagent (recombinant fibronectin or Vectofusin-1) to improve transduction 

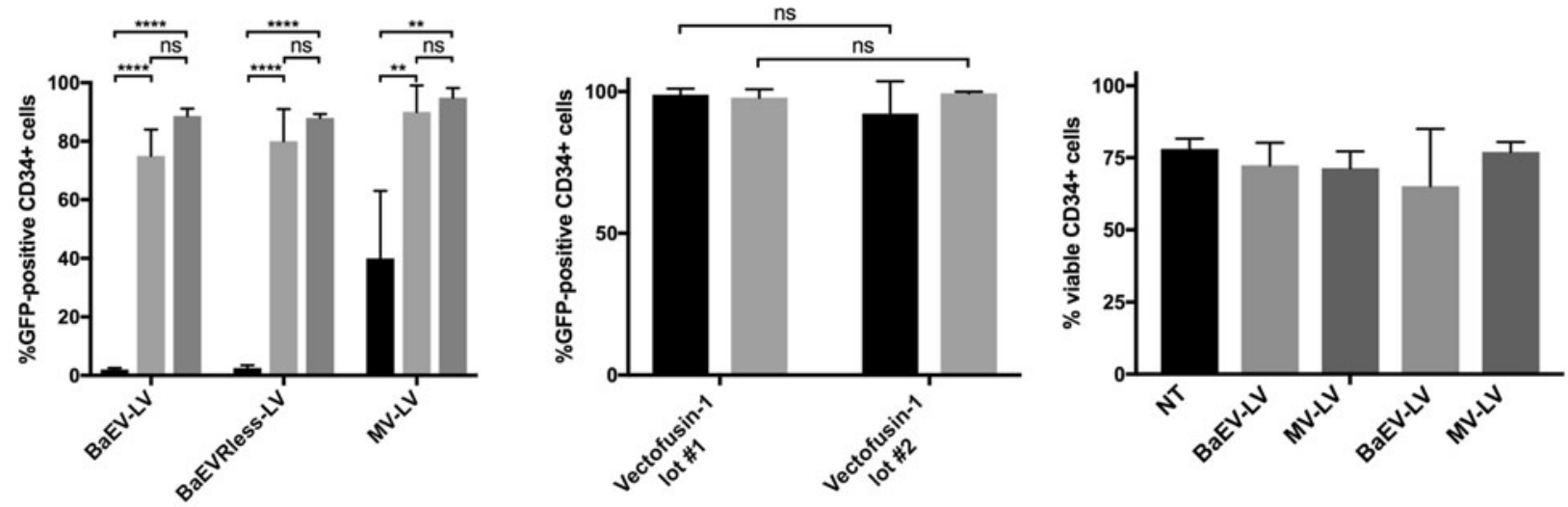

D

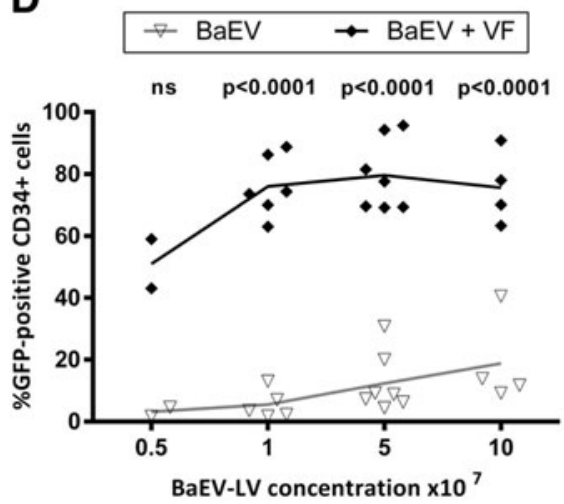

G
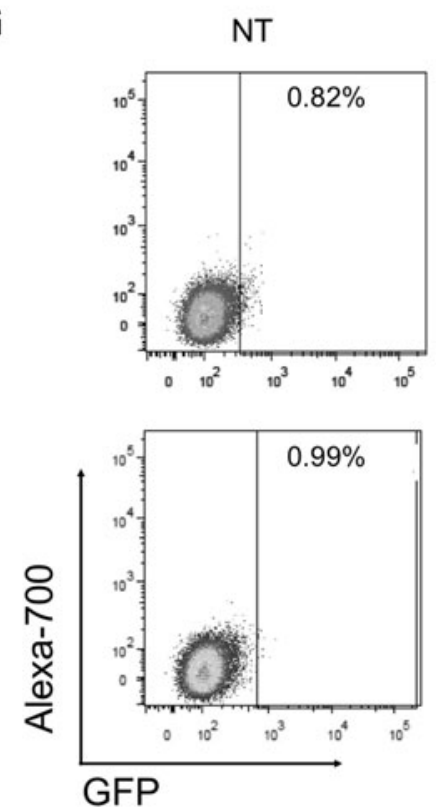

E

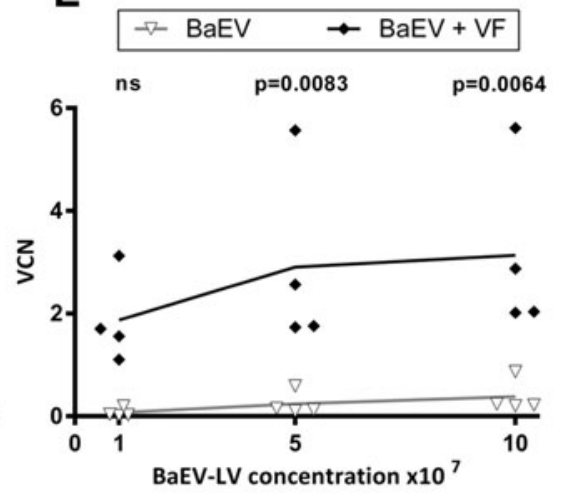

$\mathbf{F}$
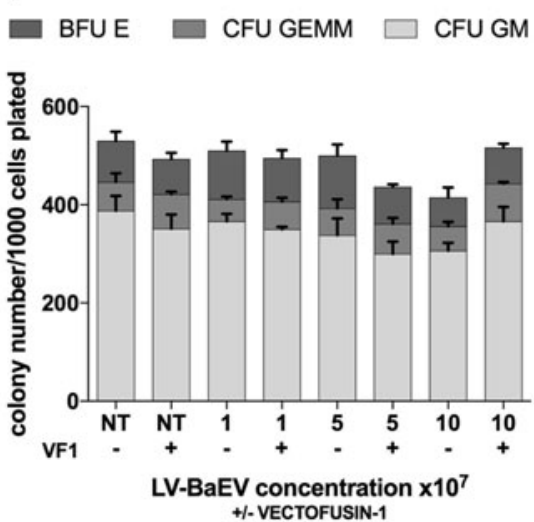

Figure 1. Vectofusin-1 $1^{\circledR}$ facilitates lentiviral transduction of hCD34 cells with the BaEV-LV and MV-LV pseudotypes. CD34 ${ }^{+}$HSCs were magnetically isolated from cord blood and were prestimulated for 16-24 h in StemMACS ${ }^{\mathrm{TM}}$ HSC Expansion Medium (A), HSC-Brew GMP Medium containing 2\% HSA (B), or X-VIVO-20 Medium (D-G), each supplemented with recombinant human TPO, SCF, IL-3, and Flt3-L. CD34 ${ }^{+}$cells were then transduced with LV encoding GFP (A-G) in the presence of Vectofusin-1 (A-G) or in recombinant fibronectin-coated plates (A) at an $\mathrm{MOI}=10(\mathbf{A}-\mathbf{C})$ or the indicated vector concentration was applied to $30,000 \mathrm{CD}^{+} 4^{+}$cells $(\mathbf{D}-\mathbf{F})$. Transduction efficiency (A, B, $\mathbf{D}$, and $\mathbf{G}$ ) and viability (C) were assessed at 4 days (A-C) or 7 days (D, G) after transduction by flow cytometry. VCN analysis was performed at day 7 (E), and for the CFU assay (F), the cells were plated in methylcellulose medium and counted at day 14. (A-C) summarizes data from four experiments while each dot in (D) and (E) represents an individual experiment. (F) Shows CFU data from two experiments, (G) shows flow cytometric data from a representative experiment in which cells were transduced with $5 \times 10^{7} \mathrm{TU} / \mathrm{mL}$ of BaEV-LV or VSVG-LV in the presence or absence of Vectofusin-1. Statistical analyses were performed using unpaired $t$-tests and one-way ANOVA. ${ }^{* * * *} p<0.0001 ;{ }^{* *} p>0.01$; ns, not significant. BaEV, baboon endogenous retrovirus; GFP, green fluorescent protein; HSA, human serum albumin; HSC, hematopoietic stem cell; $\mathrm{MOI}$, multiplicity of infection; MV-LV, measles virus-lentiviral vector; NT, not transduced; TU, transducing unit; VCN, vector copy number; VSVG, vesicular stomatitis virus G protein. 
from $9.3 \%$ to $54.2 \%$ or $61.2 \%$, respectively. In contrast, there was no significant enhancement of VSVG-LV TCT observed in the presence of Vectofusin-1 (49\% vs. $48.6 \%$ with no reagent; Fig. 2A), whereas recombinant fibronectin mildly improved transduction efficiency to $61.7 \%$.

Interestingly, Vectofusin-1, in combination with RD114-LV, can also efficiently transfer a gene of interest into $\mathrm{T}$ cells that are not TCR-stimulated, but only cultivated in cell culture medium containing IL-7 (MOI 5, 26\%; Fig. 2B). Efficient transduction of these minimally manipulated $\mathrm{T}$ cells with BaEV-LV and MV-LV, in accordance with our previous results, ${ }^{47}$ presents the option of modifying $T$ cells without inducing their differentiation or expansion. Minimal manipulation of the $\mathrm{T}$ cells would reduce manufacturing times while generating a product that may have a more favorable in vivo phenotype.

Another blood cell population, which is refractive to modification with VSVG-LV, is primary B cells (Fig. 2C). Even when used at MOI $=100$, almost no B cells (1.7\%) express the GFP marker protein. In contrast, both BaEVRless-LV and MV$\mathrm{LV}$ are able to transduce $\mathrm{B}$ cells at $\mathrm{MOI}=10$ at high efficiency (37.9\% and 58.3\%, respectively), and this
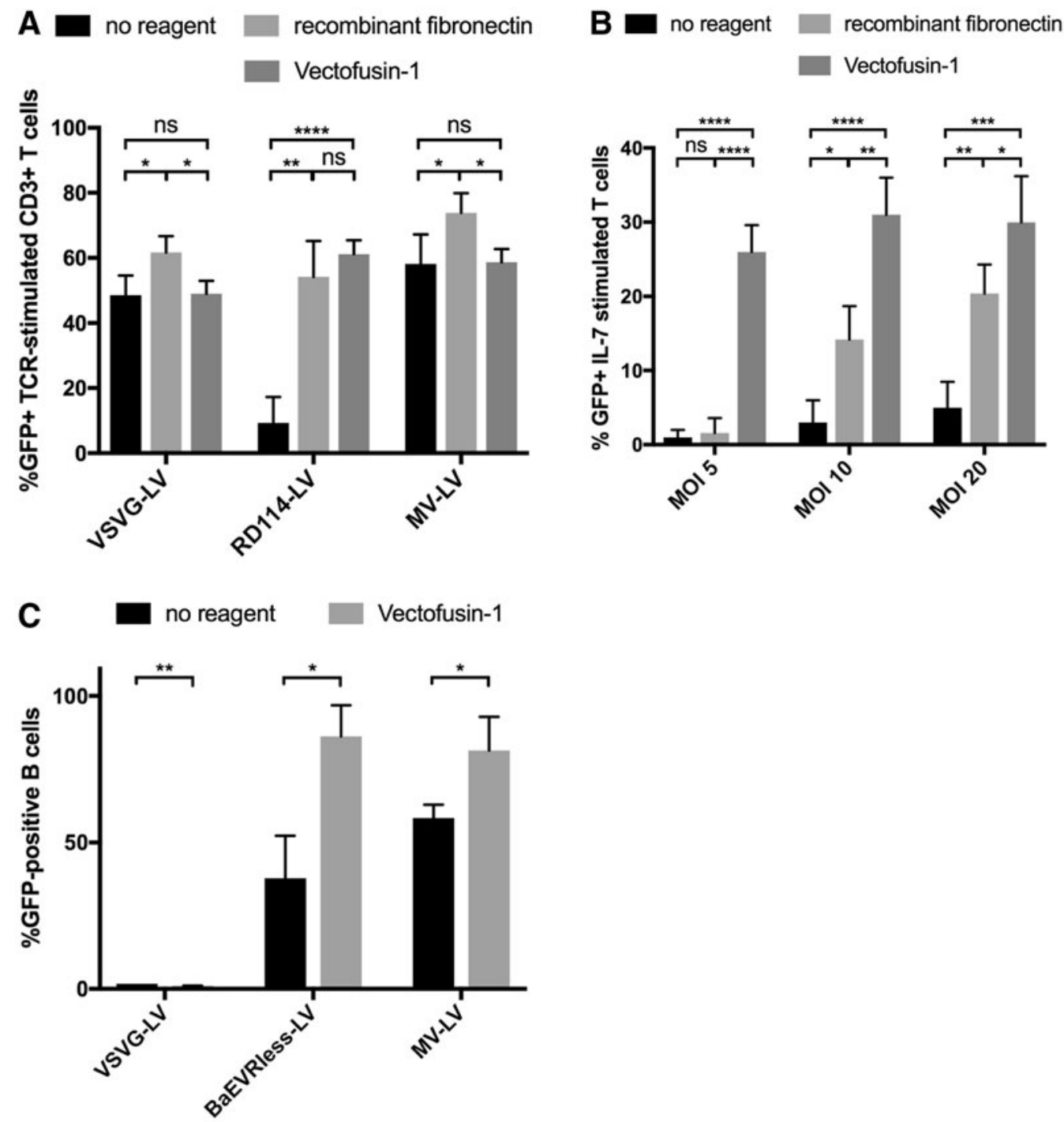

Figure 2. Vectofusin-1 augments LV transduction of both TCR- and IL-7-stimulated human T cells and BCR-stimulated B cells. Isolated human CD3 ${ }^{+}$cells were prestimulated with T Cell TransAct + IL-2 (A) or IL-7 treatment only (B). Human B cells were activated with Pansorbin A and IL-2 overnight (C, $n=3$ ). IL-7-treated T cells were transduced with RD114-LV (B); the other cell types $(\mathbf{A}, \mathbf{C})$ were transduced with the indicated LV pseudotypes at an MOI=10 (except for VSVG-LV with an $\mathrm{MOI}=100$ ) without additives, in the presence of recombinant fibronectin or Vectofusin-1. The transduction efficiencies were determined 4 days (A) or 6 days (B) or 2 days (C) after transduction by flow cytometry. Experiments were performed with four (A, B) or three (C) independent donors and viral vector preparations. Statistical analyses were performed using unpaired $t$-tests. ${ }^{* * *} p<0.0001$; ${ }^{* *} p<0.001$; ${ }^{* *} p>0.01 ;{ }^{*} p<0.05$; ns, not significant. BCR, B cell receptor; TCR, T cell receptor. 
transduction can be enhanced by prior incubation with Vectofusin-1 (86.1\% and 81.3\%, respectively).

\section{MV-pseudotyped vectors maintain their ligand specificity in the presence of Vectofusin-1}

VSVG-LV are believed to enter cells in an identical manner to the VSV envelope donor by endocytotic means after binding the LDL receptor, with virus-cell fusion events taking place in the endosome, allowing transfer of the viral genome to the cell cytoplasm. ${ }^{48}$ In the case of MV-LV, receptor binding and fusion events are $\mathrm{pH}$-independent and take place at the cell surface. ${ }^{49}$ After complexation with Vectofusin-1, it might be supposed that the natural receptor uptake mechanism could be bypassed by unspecific binding to the target cell membrane. This in turn might interfere with the specific entry of receptor retargeted MV-LV.

To investigate this, a mixture of CD20 $0^{+}$Raji and CD20- SupT1 cells were transduced at MOI $=0.05$ with a CD20-targeted MV-LV, in which a singlechain fragment is fused to the $\mathrm{H}$ protein that has been blinded for its natural receptors (aCD20-MV$\mathrm{LV}^{29}$ ), in the presence and absence of Vectofusin-1. The SupT1 cells had previously been labeled with a cell tracking dye to allow easy discrimination of target and nontarget cells by flow cytometry. Precomplexation of aCD20-MV-LV with Vectofusin-1 improved transduction efficiency by a factor of almost $5(17.8 \%$ to $85.6 \%$ GFP-positive cells; Fig. 3) with only minimal off-target effects $(0.3 \%$ GFP-positive CD20-SupT1 cells in the presence of Vectofusin-1 compared with $0 \%$ without the additive; Fig. 3A), indicating that the ligand specificity of the targeted vector is maintained.

\section{Vectofusin-1 enhances transduction of TCR-stimulated primary T cells with RV}

Murine RV are a commonly used laboratory gene transfer workhorse. Stable packaging cell lines are often used to generate Amphotropic, Ecotropic, GALV-, or RD114-pseudotyped vector particles. ${ }^{50,51}$ We assessed whether Vectofusin-1 is a suitable reagent to enhance transduction of target cells with RV based on the murine leukemia virus. Human T cells were magnetically enriched and were activated by cross-linking the TCR with TransAct T Cell Reagent. Two days later, the $T$ cells were transduced at $\mathrm{MOI}=1$ or 2 with viral vectors encoding GFP in the presence or absence of Vectofusin-1. As an additional parameter, it was assessed whether a spinoculation protocol could further increase the efficiency of vector-Vectofusin-1 complex delivery and uptake to the target cells.
Vectofusin-1 significantly enhanced transduction with both GALV-RV and RD114-RV (from 5.5\% to $14.3 \%$ [GALV] and from $0.9 \%$ to $16.6 \%$ [RD114]; Fig. 4A, B), while the inclusion of a spinoculation step resulted in the generation of the highest proportion of modified T cells (35.1\% [GALV], 39.1\% [RD114]).

\section{The generation of functional CAR T cells using RV and Vectofusin-1}

Autologous CAR $\mathrm{T}$ cell therapies are showing tremendous potential in treating liquid tumors. ${ }^{52-54}$ Many of these cellular gene therapies use RV to reprogram the patients' $\mathrm{T}$ cells. We assessed the suitability of Vectofusin-1 to be implemented in the cell manufacturing workflow. To ascertain whether cells modified with Vectofusin-1 maintain functionality, $T$ cells were isolated from 2 healthy donors and were modified with a clinical-grade GALV-RV encoding an ErbB2-specific CAR, without reagent, with Vectofusin-1, or with recombinant fibronectin and in combination with spinoculation.

Both recombinant fibronectin and Vectofusin-1 improved the proportion of $\mathrm{T}$ cells expressing the CAR markedly (from $7 \%$ to $32.8 \%$ and $17.1 \%$, respectively; Fig. 5A). Seven days after the genetic modification, the CAR T cells were incubated with target cells expressing ErbB2 (MCF-7) or lacking the antigen (SupT1) for $24 \mathrm{~h}$ at an effector:target ratio of $1: 2$, and the supernatants were analyzed for the secretion of inflammatory cytokines. As a positive control, T cells were stimulated with PMA/ ionomycin. The CAR T cells produced similar levels of inflammatory cytokines upon contact with their cognate antigen (Fig. 5B), irrespective of their method of manufacture, indicating that Vectofusin-1 is a good candidate enhancement agent for implementation in CAR T cell manufacturing.

\section{Efficient implementation of Vectofusin-1 \\ in an automated, closed-system $\mathrm{T}$ cell manufacturing process}

Full automation of clinical-scale production of genetically engineered $\mathrm{T}$ cells is challenging when solid-phase transduction enhancers such as recombinant fibronectin are used. We therefore assessed transduction enhancement in the presence of soluble Vectofusin-1 in a single-platform, closed system, the CliniMACS Prodigy ${ }^{\circledR}$ (Fig. 6A), using the singleuse tubing set CliniMACS Prodigy TS 520. A spinoculation transduction protocol was integrated as a flexible programmable activity into the existing automated lentiviral TCT process. In this new activity, the viral vector complexed with Vectofusin-1 is added to the tubing set and mixed with the target cells, which can then be spun at $400 \mathrm{~g}$ for $2 \mathrm{~h}$ to 
A Gating
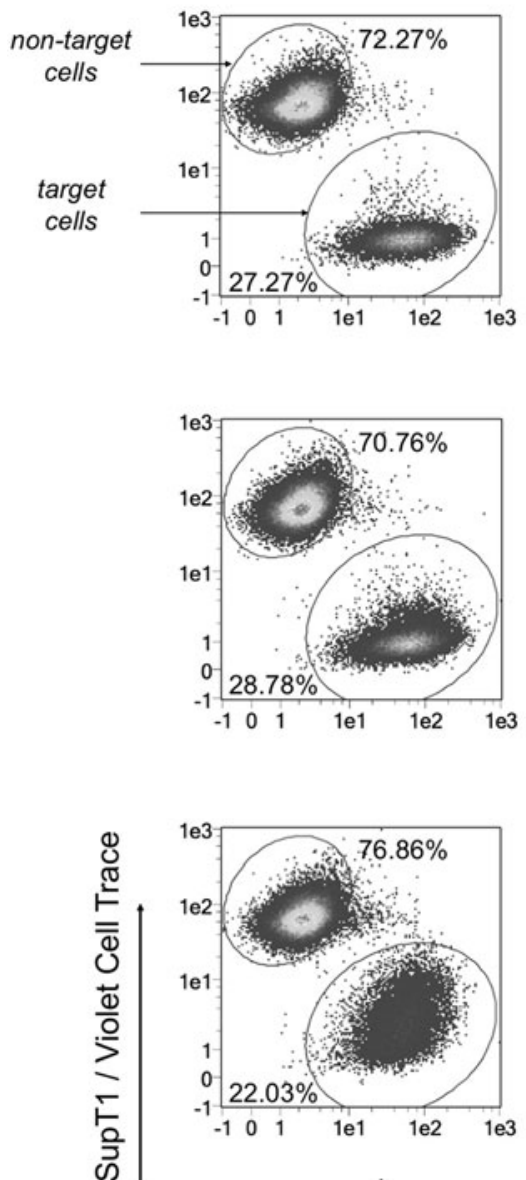

Raji / CD20-PerCP-Vio770
Raji

(target cells)
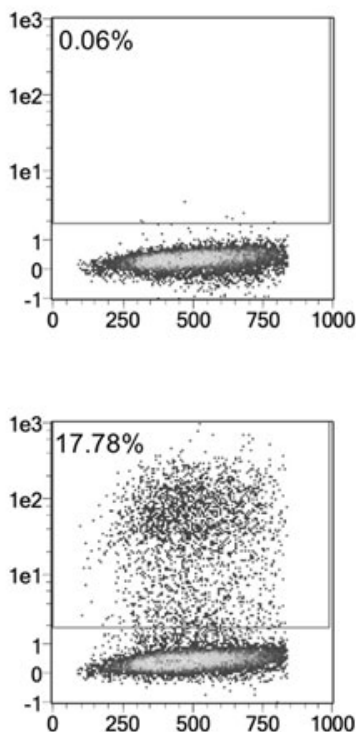

윤

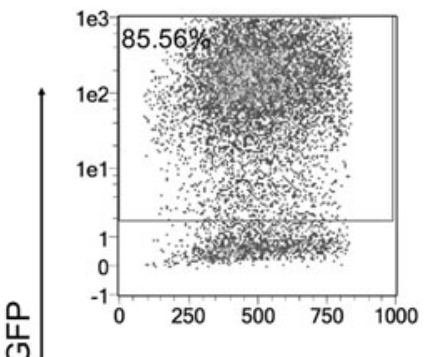

SSC
SupT1

(non-target cells)
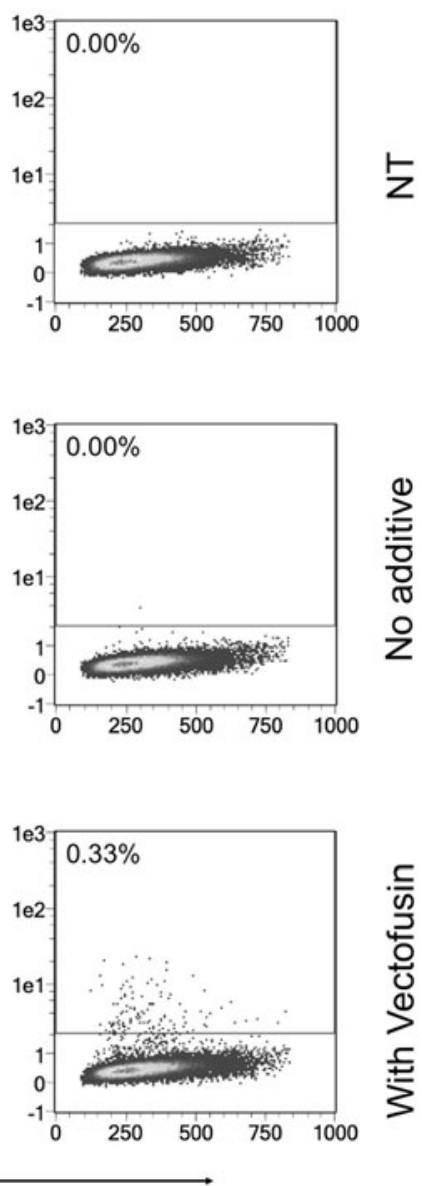

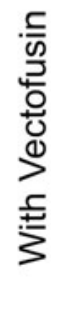

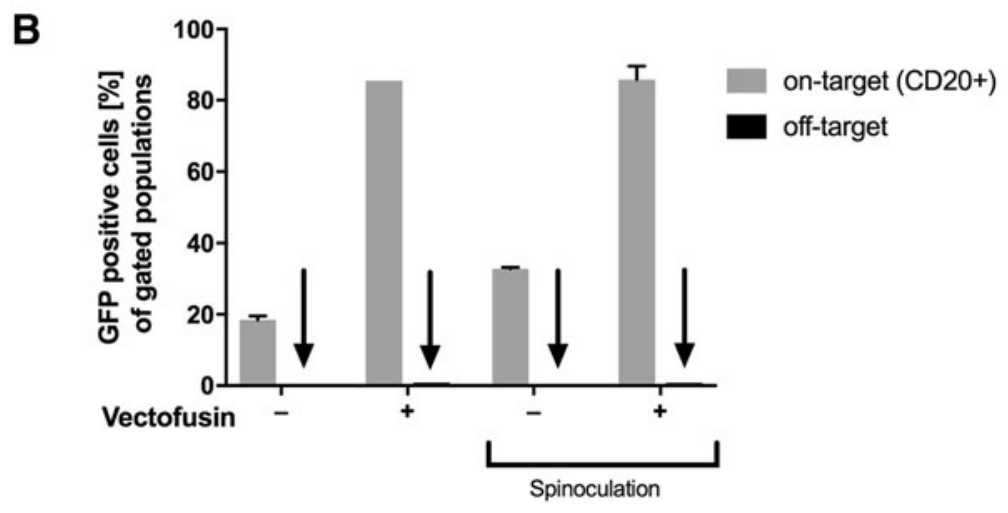

Figure 3. MV-pseudotyped vectors maintain their ligand specificity in the presence of Vectofusin-1. An equal mixture of CD20 ${ }^{+}$Raji cells and violet $d y e-l a b e l e d ~ S u p T 1$ cells were transduced in duplicate with MV-H-scFv-CD20-pseudotyped LV encoding GFP at an MOI $=0.05$ in the presence or absence of Vectofusin- 1 and with or without a spinoculation step $\left(2 \mathrm{~h}\right.$ centrifugation at $400 \mathrm{~g}, 32^{\circ} \mathrm{C}$ ). Cells were then stained $72 \mathrm{~h}$ post-transduction with anti-CD20-PerCP-Vio770 and analyzed by flow cytometry. Target and nontarget cells were differentiated by expression of CD20 and violet dye label, and the proportions of each cell population expressing GFP were quantified. (A) Cells transduced without spinoculation, (B) summary data with and without spinoculation. Data from a representative experiment are shown. scFv, single-chain antibody.

improve vector-target cell colocalization. The feasibility of automated transduction was assessed using RV encoding GFP and compared with small-scale experiments performed with identical reagents in tissue culture plates.
Transduction rates of enriched $\mathrm{CD} 4^{+} / \mathrm{CD}^{+} \mathrm{T}$ cells transduced with GALV-RV (Fig. 6B) and RD114-RV (Fig. 6D) were increased in the presence of Vectofusin-1 in both small scale and in the automated closed system (Supplementary Fig. S2). 

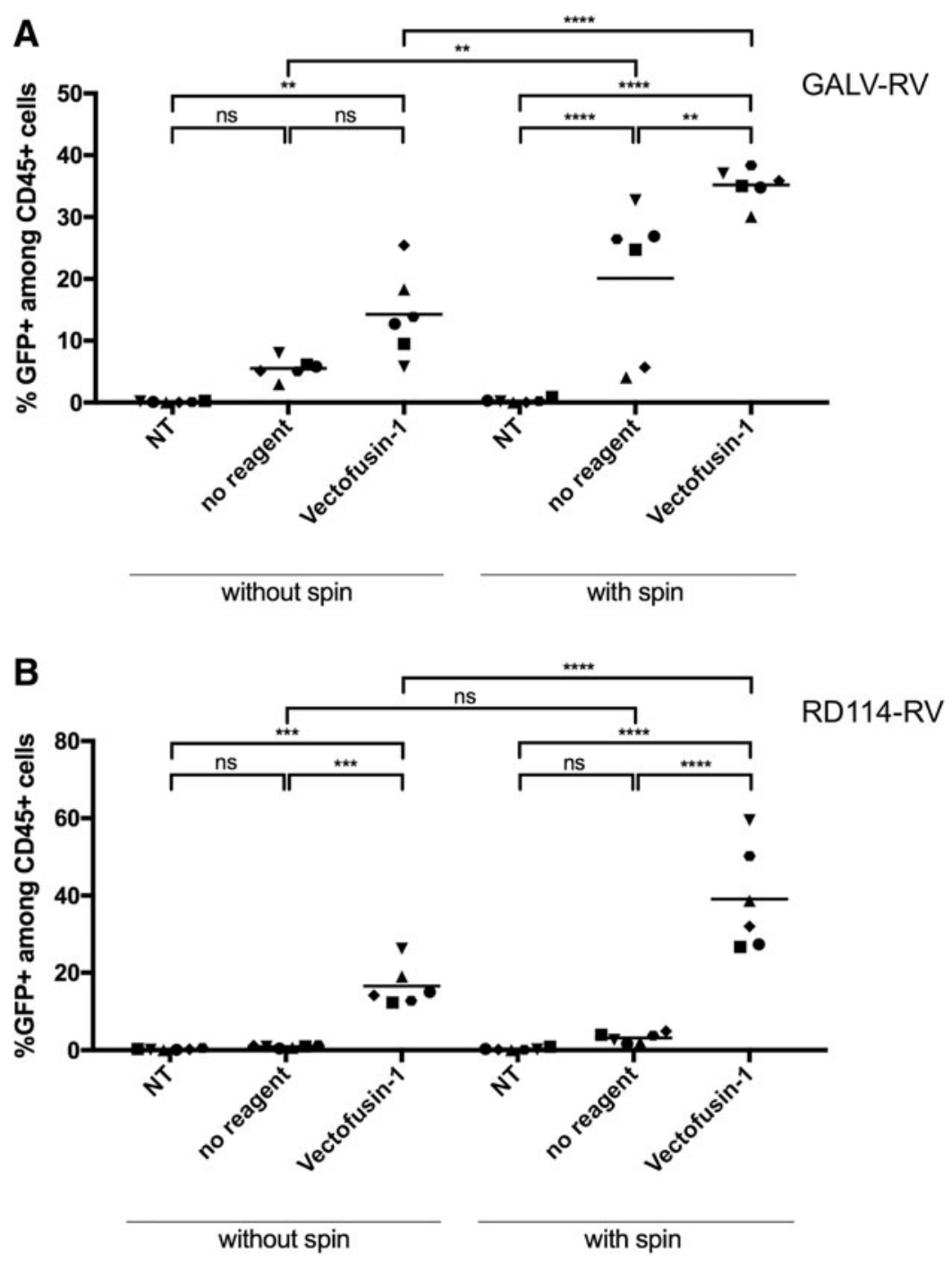

Figure 4. Vectofusin-1 enhances transduction of TCR-stimulated primary T cells with RV. Primary human T cells were activated with TransAct T Cell Reagent in TexMACS medium supplemented with IL-2. Two days after activation, T cells were transduced with RV encoding GFP, pseudotyped with GALV (M0I 1; A) and RD114 (MOI 2; B); $n=6$. Cultures were washed 6 or $24 \mathrm{~h}$ after transduction and analyzed on day 7 of cultivation via flow cytometry. Transduction efficiencies could be increased by adding Vectofusin- $1(10 \mu \mathrm{g} / \mathrm{mL})$. Highest transduction efficiencies were obtained using a spinoculation protocol $(2 \mathrm{~h}$ centrifugation at $400 \mathrm{~g}$, $32^{\circ} \mathrm{C}$ ). A one-way ANOVA was performed to determine significance. ${ }^{* *} p<0.01 ;{ }^{* * *} p<0.001 ;{ }^{* * *} p<0.0001$; ns, not significant. GALV, gibbon ape leukemia virus; RV, gammaretroviral vectors.

Transductions with GALV-RV and RD114-RV performed on the CliniMACS Prodigy yielded results comparable to the respective small-scale controls (Fig. 6C and Supplementary Fig. S2). After automated transduction on day 2 , the $\mathrm{T}$ cells were washed to remove excess viral vector and stimulation reagent and further expanded in the tubing set using the automated feeding and media exchange activities of the TCT Process. The presence of Vectofusin-1 did not influence the expansion behavior or viability of the $T$ cells transduced with either pseudotype (Fig. 6E, F), the phenotype of the T cells (Fig. 6G), or the composition of the cell product (Supplementary Fig. S3).

After completion of the process and the automated formulation and harvest in isotonic $\mathrm{NaCl}$ solution, an average of $1.16 \times 10^{9}$ viable $\mathrm{T}$ cells (mainly central memory phenotype, Fig. 6G) could be generated, with an average of $5.12 \times 10^{8}$ viable transduced cells in total (data not shown). This would be an adequate dose of genetically modified $\mathrm{T}$ cells for application in an oncological setting, demonstrating that, similar to the established lentiviral TCT process, ${ }^{43}$ an automated GMP manufacturing of $\mathrm{T}$ cell products is possible using an RV platform and Vectofusin-1.

\section{DISCUSSION}

There are a number of challenges faced by researchers, clinicians, and commercial entities who 
A

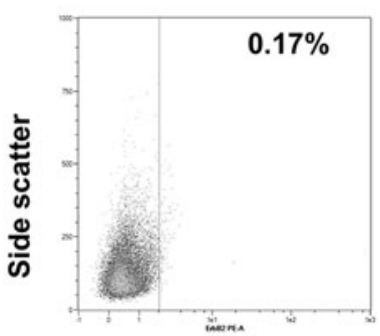

no reagent

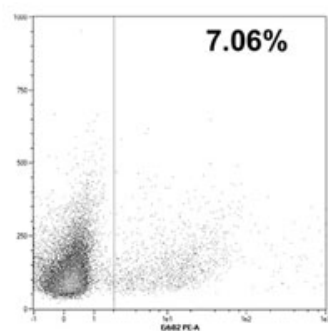

Vectofusin-1

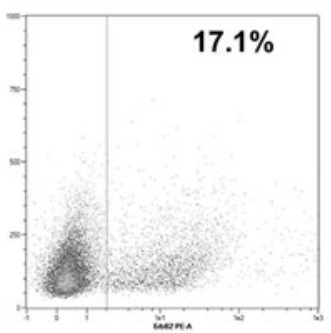

recombinant fibronectin

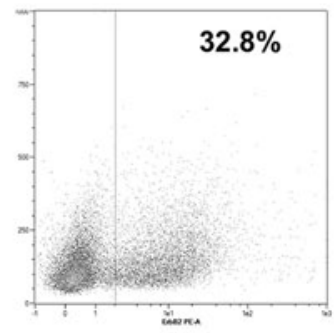

ErbB2 CAR expression

B

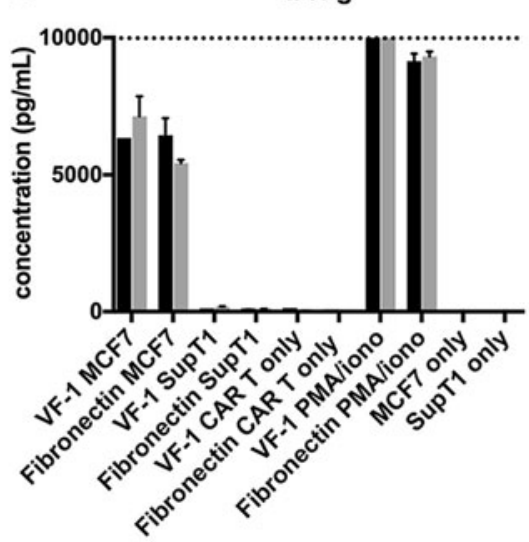

TNFa

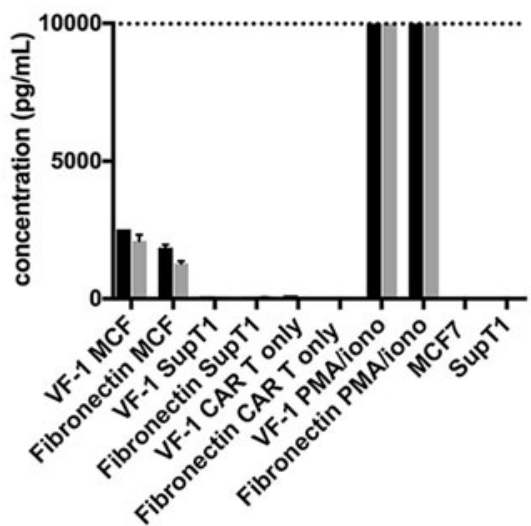

Figure 5. CAR T cells generated with Vectofusin-1 are functional. Primary human T cells from two donors were transduced in the presence of Vectofusin-1 with an RD114-pseudotyped RV, MSGV-4D5-CD8-28BBZ, encoding an ErbB2-specific CAR at an MOI=1. CAR-expressing T cells were identified by flow cytometry using an ErbB2-Fc fusion protein and anti-Fc-PE conjugate (A). Seven days after the genetic modification, the T cells were incubated with target cells expressing ErbB2 (MCF-7) or lacking the antigen (SupT1) for $24 \mathrm{~h}$ at an effector:target ratio of 1:2 and the supernatants were analyzed for the secretion of inflammatory cytokines (B), donor 1 black columns, donor 2 gray columns. As a positive control, T cells were stimulated with PMA/ionomycin. CAR T cells or cell lines alone served as negative control samples. CAR, chimeric antigen receptor.

want to permanently genetically modify primary human cells. The efficiency, safety, cost, and ease of use will determine which method is best suited for the planned application. While nonviral approaches, to modify target cells such as gene editing nucleases (e.g., CRISPR/cas9 ribonuclear proteins), are rapidly gaining in popularity and are widely used in the research setting, they will require some further development before they are ready for routine clinical use. ${ }^{55}$ Currently, the majority of ex vivo modified gene therapy products have been generated using RV and LV pseudotyped with VSVG, RD114, or GALV envelope proteins. ${ }^{52,53,56,57}$

One of the costliest clinical applications is the genetic modification of human HSCs. Viral modification of these cells is extremely inefficient, with large excesses of viral vector particles being required to get an acceptable gene insertion efficiency. ${ }^{45,58,59}$ There is a requirement to find alternative methods to improve the viral delivery to reduce viral vector requirements and costs.
One approach has been the development of new pseudotype LV such as BaEV-LV and MV-LV. Both BaEV-LV and MV-LV show good transduction efficiencies in $\mathrm{HSCs}^{24}$ and allow even transduction of nonstimulated resting $\mathrm{HSCs}^{24,25}$ However, only relatively low titers of vector can currently be obtained during manufacturing, ${ }^{24,30}$ leading us to examine whether a transduction enhancer such as Vectofusin-1 could improve the transduction efficiencies.

We compared the soluble peptide, Vectofusin-1, with an established method using recombinant fibronectin to coat cell culture surfaces. Both BaEV-LV and MV-LV transduction of HSCs were enhanced to a similar extent using Vectofusin-1 compared with the recombinant fibronectin using both research quality and GMP-compatible reagents, while maintaining cell viability and colony-forming potential. The number of genomic integrations was related to the amount of viral vector applied, indicating that it is unlikely that only aggregates of viral vector are being 
A

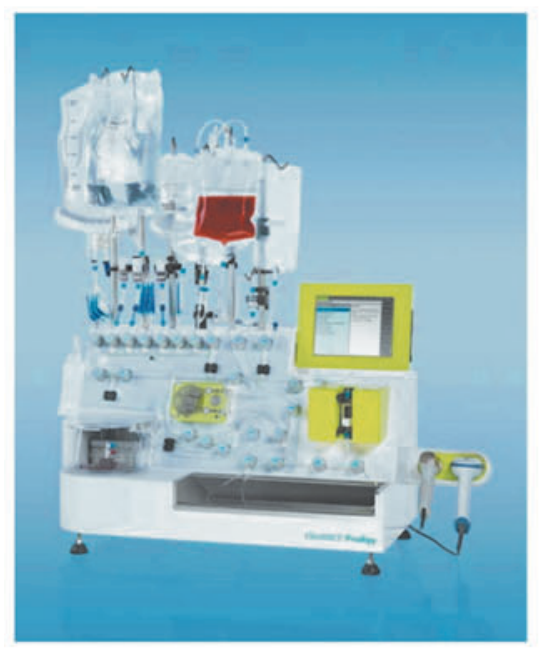

C
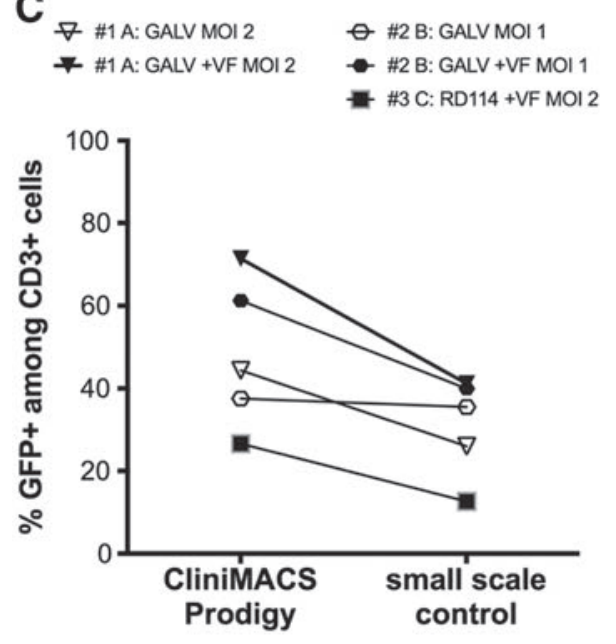

E

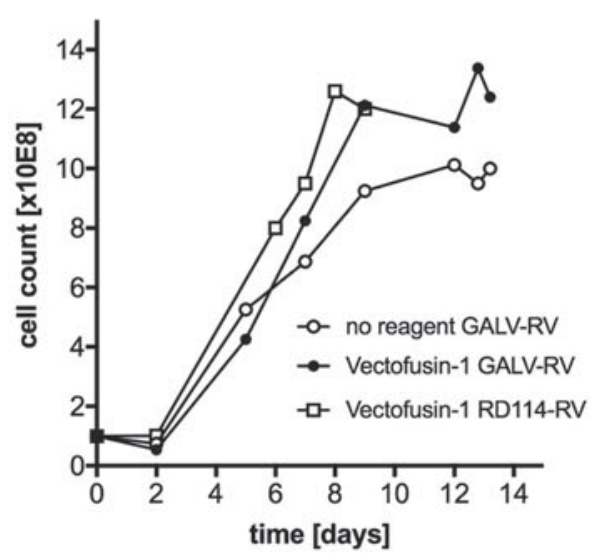

B
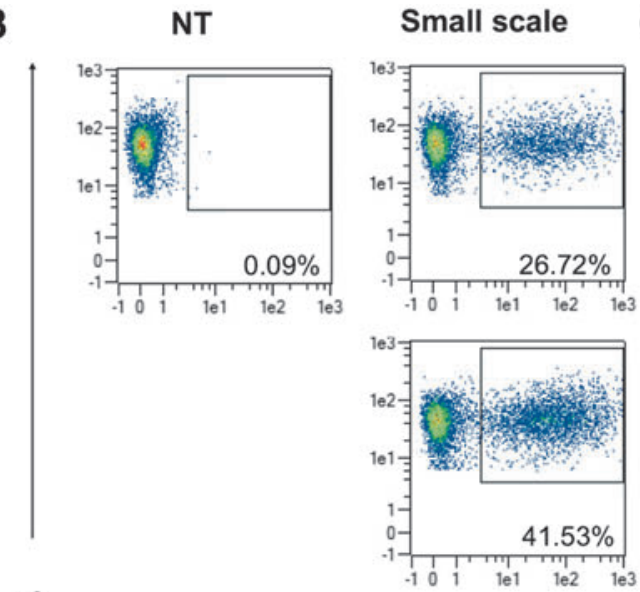

o̊

GFP

Percentage indicates frequency among $\mathrm{CD} 45+\mathrm{CD} 3+$ cells

D

NT

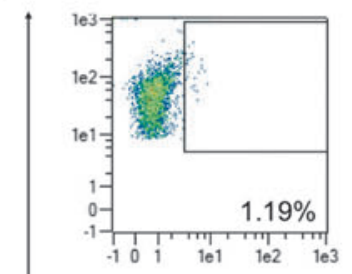

Small scale
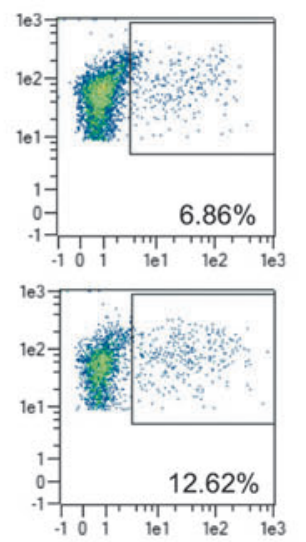

CliniMACS Prodigy
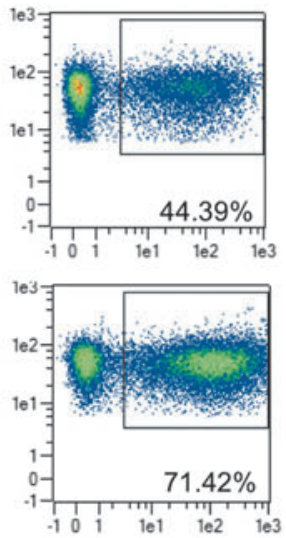

京

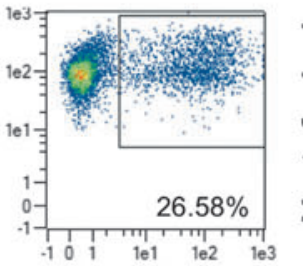
GFP

Percentage indicates frequency among CD45+CD $3+$ cells

$\mathbf{F}$

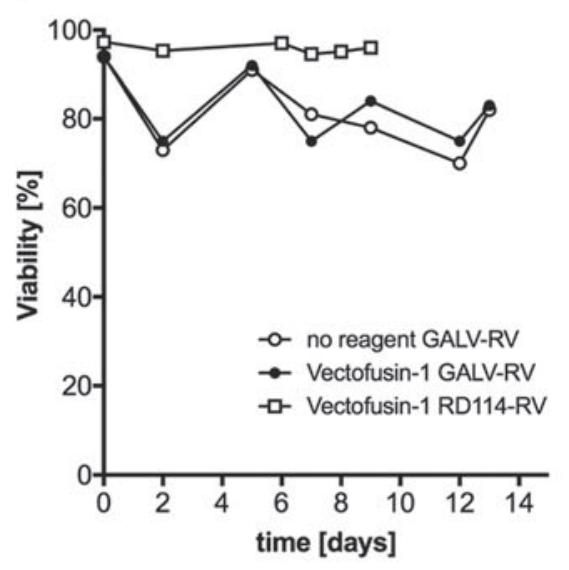

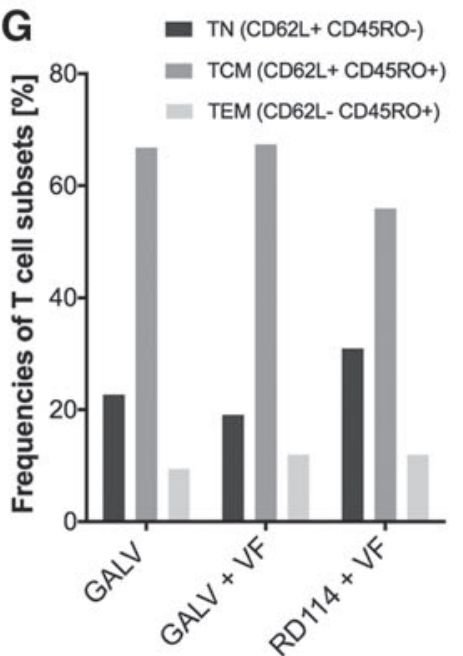

Figure 6. Efficient implementation of Vectofusin-1 in an automated, closed-system T cell manufacturing process. Human T cells were magnetically enriched on the CliniMACS Prodigy instrument (A) and were either cultivated in tissue culture plates or in the single-use tubing set attached to the instrument. Subsequent activation, transduction, and cell expansion steps were then either performed manually (tissue culture plates) or in a fully automated manner using the TCT process using identical reagents, comparison data shown in (C). Enriched $\mathrm{CD}^{+} / \mathrm{CD}^{+} \mathrm{T}$ cells were transduced at an $\mathrm{MOI}=2$ on day 2 with spinoculation at $400 \mathrm{~g}$ for $2 \mathrm{~h}$ using gammaretroviral GFP vector pseudotyped with GALV (B) or RD114 (D). Transgene expression was assessed by flow cytometry on day 7 . The T cells were further expanded in the CliniMACS Prodigy using the automated feeding and media exchange activities of the TCT process. Samples were taken regularly during cultivation to determine cell density (E) and viability (F) by flow cytometry. Further definition of the T cell subpopulations (naive, TN; central memory TCM; effector memory; TCM) present at day 13 was determined by analysis of CD62L and CD45R0 expression by flow cytometry (G). TCT, T cell transduction. 
taken up. Importantly, the modified CD $34^{+}$cells also showed successful long-term engraftment and maintained high-level transduction in their progeny ( $\mathrm{T}$ and $\mathrm{B}$ cells) in an NSG mouse model, indicating that long-term SCID repopulating cells were transduced (Supplementary Fig. S3). This is in agreement with earlier studies where CD34 ${ }^{+}$cells were modified with BaEV-LV and MV-LV in the presence of recombinant fibronectin. ${ }^{24,25}$

This performance bodes well for upscale and automation of HSC modification protocols with these alternative pseudotypes. One HSC gene therapy application with an urgent need is the treatment of Fanconi anemia, where prolonged cultivation of the cells leads to cell death and a rapid transduction without lengthy pre-activation is desired. ${ }^{60}$ Here, a combination of the new pseudotypes and Vectofusin-1 could be of great advantage.

Other cells that are challenging to transduce include primary B cells and nonstimulated T cells. Here, we show that B cells can be efficiently modified using BaEV-LV and MV-LV in combination with Vectofusin-1. B cells already express the ASCT-1/2 entry receptor for BaEV, allowing BaEV-LV transduction, but do not express the low density lipoprotein receptor (LDLR), the VSVG entry receptor, even after strong $B$ cell receptor (BCR) signaling. ${ }^{26,61}$ Similarly, MV-LV can effectively transduce B cells due to the presence of the CD150/SLAM receptor on unstimulated B cells. ${ }^{62}$ In both cases, the use of Vectofusin-1 further improved the transduction efficiency. B cells have previously been shown to have potential for the production of therapeutic proteins such as Factor $\mathrm{IX}^{26}$ or in vivo therapeutic antibody production ${ }^{27}$ so further optimization of transduction procedures as shown here may allow this approach to translate toward the clinic.

Similarly, resting $\mathrm{T}$ cells are not transduced efficiently by VSVG-LV, even at high vector doses, also due to the absence of the LDLR. As we have shown previously, ${ }^{61}$ TCR stimulation leads to strong LDLR upregulation and coincides with permissiveness for VSVG-LV. Treatment of T cells with IL-7 also results in an upregulation of LDLR in a subpopulation of the cells and leads to some susceptibility to VSVG-LV transduction. ${ }^{46} \mathrm{RD} 114-\mathrm{LV}$ is a pseudotype that is dependent on enhancement reagents, and we show here that Vectofusin-1 demonstrates a more effective support of lentiviral modification than recombinant fibronectin in these minimally stimulated $\mathrm{T}$ cells that only receive an IL7R signal (Fig. 2B).

In the current standard of manufacturing, $\mathrm{T}$ cells are stimulated via their TCR using antibodies directed against the CD3 and CD28 molecules, which result in full cell cycle induction and efficient LV transduction. ${ }^{46}$ The T cells are normally further expanded for a period of 1-2 weeks before infusion to the patient. Reducing manufacturing times would not only be attractive to reduce costs but also to be able to treat patients more rapidly. However, the pan-activation method creates a barrier to early patient application as it would be inadvisable to infuse highly activated polyclonal $\mathrm{T}$ cells. The modification of nonstimulated $\mathrm{T}$ cells, as shown here, would allow rapid ex vivo manufacturing of the $\mathrm{T}$ cell product while reducing the potential for generation of exhausted $\mathrm{T}$ cells after a lengthy cultivation. In both cases, whether a strong TCR signal is given or only an IL7R signal, Vectofusin-1 improves transduction efficiencies with RD114-LV.

Vectofusin-1 induces the formation of nanofibrillar structures with a $10 \mathrm{~nm}$ periodicity. ${ }^{39}$ These fibrils are formed within $15 \mathrm{~min}$ in cell culture medium and interact and complex with viral vector. It is expected that the formation of aggregates between Vectofusin-1 and viral vector could alter the cellular uptake mechanisms or even bypass the normal viral receptor. For viral vectors that enter cells via endocytosis such as VSVG-LV, it has clearly been shown that complexation of the viral vector with the polycationic substance polybrene results in an effective transduction of target cells lacking the major VSVG receptor protein, LDLR. ${ }^{63}$

We therefore assessed a targeting viral vector platform where the MV hemagglutinin $(\mathrm{H})$ glycoprotein can be rendered selective by the addition of a ligand of choice to the C-terminus. This ligand can be a single-chain antibody $(\mathrm{scFv})^{29,30}$ or from another ligand family such as the DARPins. ${ }^{64}$ Using a pseudotyped viral vector that targets $\mathrm{CD} 20,{ }^{30}$ an efficient and specific targeting of CD20 ${ }^{+}$ cells is possible ${ }^{30}$ (Fig. 3). The transduction efficiency of vectors pseudotyped with both the targeted and native $\mathrm{H}$ proteins (data not shown) was enhanced by the addition of Vectofusin-1. However, the complexation with Vectofusin-1 did not induce unspecific transduction of CD20-negative SupT1 cells nor does Vectofusin-1 lead to a nonspecific targeting of T cells with MV-LV specific for CD4 or CD8, despite strong attachment of viral vector to the $\mathrm{T}$ cell surface. ${ }^{40}$ This suggests that specific binding of the MV $\mathrm{H}$ protein to the respective receptor and induction of a conformational change in $\mathrm{MV} \mathrm{F}^{65}$ are still required to enable efficient release of the viral capsid into the cytoplasm.

Synthetic peptides can easily be manufactured to high levels of purity for application in the clinic. We wanted to assess the suitability of Vectofusin-1 
in $\mathrm{T}$ cell gene therapy manufacturing workflows, as many $\mathrm{T}$ cell products expressing cancer-specific CAR or TCR currently in the clinic are using retroviral vector systems and bag- or plate-based, recombinant fibronectin-dependent transduction protocols. ${ }^{66,67}$ Vectofusin-1 has the great advantage of being a soluble reagent that does not have to be coated on a solid phase before transduction.

First of all, we demonstrated that the reagent is compatible for use with GALV-RV and RD114-RV and that transduction efficiency can be improved when an additional physical force is used to increase the local concentration of the vector on the target cells (Fig. 4). This spinoculation step was beneficial without Vectofusin-1 when using GALV$\mathrm{RV}$, possibly indicating that this vector has an intrinsic tendency to self-aggregate. However, for RD114-RV, almost no transduction could be detected in the absence of Vectofusin-1.

To investigate $\mathrm{T}$ cell functionality, we used a clinical-grade GALV-RV that encoded a CAR specific for ErbB2. This CAR has unfortunately been shown to demonstrate toxicity in the clinic ${ }^{68}$ but has been well characterized in vitro. ${ }^{57}$ Using this CAR construct, we showed that modified $\mathrm{T}$ cells recognize their cognate antigen and are activated, leading to the release of inflammatory cytokines into the supernatant.

To further understand the clinical applicability of the Vectofusin-1 peptide, we adapted our closedsystem automated workflow on the CliniMACS Prodigy instrument, the TCT process, ${ }^{43}$ to enable a retroviral transduction to be performed. To this end, the activity matrix (a flexible software module enabling users to set up and adapt the culture, washing, feeding, and transduction steps) was modified to allow larger volumes of nonconcentrated vector supernatant to be applied (rather than the customary low volumes of purified LV) and a spinoculation step was implemented. Using GFP-encoding GALV-RV and RD114-RV, we could demonstrate in a proof-of-concept experiment that an efficient automated transduction could be performed. At the end of the process, the majority of $\mathrm{T}$ cells were of the Tcm phenotype, agreeing with similar data generated with $\mathrm{LV}^{43}$ and a clinically relevant dose of modified cells ${ }^{69}$ could be generated $\left(>5 \times 10^{8} \mathrm{GFP}^{+} \mathrm{T}\right.$ cells $)$.

Vectofusin-1 is a functional alternative to recombinant fibronectin. It augments the transduc- tion of primary cells and cell lines with both RV and LV pseudotyped with a range of viral envelope proteins and has the potential to be implemented in the clinical arena in streamlined automated processes. The use of Vectofusin-1 and automated workflows has the potential to lead to reductions in hands-on time and significantly reduce costs in the GMP manufacturing of gammaretrovirusmodified $\mathrm{T}$ cell products for cancer therapies. The concomitant introduction of transduction-efficient pseudotypes such as BaEV and MV to viral vectorintensive manufacturing processes, such as modification of HSCs for the treatment of PID or other inborn blood disorders such as beta thalassemia, should further lead to a reduction of costs and the possibility of bringing these exciting therapies to a wider cross-section of patients.

\section{ACKNOWLEDGMENTS}

The authors would like to acknowledge the contribution from mothers, Dr Rigonnot, and staff of Centre Hospitalier Sud-Francilien in Evry for providing umbilical cord blood for research and the technical help from Flavien Bizot and Laetitia Menu at Genethon for some experiments. The authors thank Dr. Richard Morgan for providing the PG13-4D5-D12 retroviral vector.

\section{AUTHOR DISCLOSURE}

C.R., K.D., N.C., R.P., P.S., A.D.K., T.S., and I.C.D.J. are employees of Miltenyi Biotec. No competing financial interests exist for the remaining authors.

\section{FUNDING INFORMATION}

This project has received funding from the European Union's Horizon 2020 research and innovation program under grant agreement No 667980 (CARAT) for N.C., T.S., A.D.K., and I.C.D.J. A.G.G. and M.M. acknowledge the support of AFM/ Telethon.

\section{SUPPLEMENTARY MATERIAL}

Supplementary Figure S1

Supplementary Figure S2

Supplementary Figure S3 


\section{REFERENCES}

1. Fesnak $A D$, June $C H$, Levine $B L$. Engineered $T$ cells: the promise and challenges of cancer immunotherapy. Nat Rev Cancer 2016;16:566-581.

2. Wang $X$, Rivière I. Genetic engineering and manufacturing of hematopoietic stem cells. Mol Ther Methods Clin Dev 2017;5:96-105.

3. Kaiser AD, Assenmacher M, Schröder B, et al Towards a commercial process for the manufacture of genetically modified T cells for therapy. Cancer Gene Ther 2015;22:72-78.

4. Levine BL, Miskin J, Wonnacott K, et al. Global manufacturing of CAR T cell therapy. Mol Ther Methods Clin Dev 2017;4:92-101.

5. Hodgson CP, Solaiman F. Virosomes: cationic liposomes enhance retroviral transduction. Nat Biotechnol 1996:14:339.

6. Cornetta K, Anderson WF. Protamine sulfate as an effective alternative to polybrene in retroviralmediated gene-transfer: implications for human gene therapy. J Virol Methods 1989;23:187-194.

7. Davis HE, Rosinski M, Morgan JR, et al. Charged polymers modulate retrovirus transduction via membrane charge neutralization and virus aggregation. Biophys J 2004;86:1234-1242.

8. Krylova 00, Melik-Nubarov NS, Badun GA, et al Pluronic L61 accelerates flip-flop and transbilayer doxorubicin permeation. Chemistry 2003;9:39303936

9. Hanenberg $H$, Xiao XL, Dilloo D, et al. Colocalization of retrovirus and target cells on specific fibronectin fragments increases genetic transduction of mammalian cells. Nat Med 1996;2:876.

10. Kotani H, Newton PB, Zhang S, et al. Improved methods of retroviral vector transduction and production for gene therapy. Hum Gene Ther 1994;5:19-28.

11. Liu H, Hung Y, Wissink SD, et al. Improved retroviral transduction of hematopoietic progenitors by combining methods to enhance virus-cell interaction. Leukemia 2000;1640:307-311.

12. Plank C, Anton M, Rudolph C, et al. Enhancing and targeting nucleic acid delivery by magnetic force. Expert Opin Biol Ther 2003;3:745-758.

13. Sanchez-Antequera Y, Mykhaylyk 0, van Til NP, et al. Magselectofection: an integrated method of nanomagnetic separation and genetic modification of target cells. Blood 2011;117:e171e181.

14. Wang CX, Torbett BE. Role of the mammalian target of rapamycin pathway and rapamycin in lentiviral vector gene transduction of hematopoietic stem cells. Curr Opin Hematol 2015;22 302-308

15. Lewis G, Christiansen L, McKenzie J, et al. Staurosporine increases lentiviral vector transduction efficiency of human hematopoietic stem and progenitor cells. Mol Ther Methods Clin Dev 2018:9:313-322.
16. Heffner GC, Bonner M, Christiansen L, et al. Prostaglandin E2 increases lentiviral vector transduction efficiency of adult human hematopoietic stem and progenitor cells. Mol Ther 2018; 26:320-328.

17. Moussy A, Papili Gao N, Corre G, et al. Constraints on human CD34+ cell fate due to lentiviral vectors can be relieved by valproic acid. Hum Gene Ther 2019;30:1023-1034.

18. Kohn DB, Hollis RP. Envelope, please. and the award goes to.. Blood 2014;124:1203-1204.

19. Lévy C, Verhoeyen E, Cosset F-L. Surface engineering of lentiviral vectors for gene transfer into gene therapy target cells. Curr Opin Pharmacol 2015;24:79-85

20. Costello E, Munoz M, Buetti E, et al. Gene transfer into stimulated and unstimulated T lymphocytes by HIV-1-derived lentiviral vectors. Gene Ther 2000;7:596-604.

21. Miyoshi H, Smith KA, Mosier DE, et al. Transduction of human $\mathrm{CD} 34+$ cells that mediate longterm engraftment of NOD/SCID mice by HIV vectors. Science 1999:283:682-686.

22. Sandrin V, Boson B, Salmon P, et al. Lentiviral vectors pseudotyped with a modified RD114 envelope glycoprotein show increased stability in sera and augmented transduction of primary lymphocytes and CD34+ cells derived from human and nonhuman primates. Blood 2002;100:823832.

23. Stornaiuolo A, Piovani BM, Bossi S, et al. RD2MolPack-Chim3, a packaging cell line for stable production of lentiviral vectors for anti-HIV gene therapy. Hum Gene Ther Methods 2013;24:228240.

24. Girard-Gagnepain A, Amirache F, Costa C, et al. Baboon envelope pseudotyped LVs outperform VSV-G-LVs for gene transfer into early-cytokinestimulated and resting HSCs. Blood 2014;124 1221-1231.

25. Lévy C, Amirache F, Girard-Gagnepain A, et al. Measles virus envelope pseudotyped lentiviral vectors transduce quiescent human HSCs at an efficiency without precedent. Blood Adv 2017;1: 2088-2104.

26. Levy C, Fusil F, Amirache F, et al. Baboon envelope pseudotyped lentiviral vectors efficiently transduce human $\mathrm{B}$ cells and allow active factor IX B cell secretion in vivo in NOD/SCID $\gamma \mathrm{C}-/$ - mice. J Thromb Haemost 2016;14:2478-2492.

27. Fusil F, Calattini $S$, Amirache F, et al. A lentiviral vector allowing physiologically regulated membrane-anchored and secreted antibody expression depending on B-cell maturation status. Mol Ther 2015;23:1734-1747.

28. Frecha $C$, Lévy $C$, Cosset $F$, et al. Advances in the field of lentivector-based transduction of $T$ and $B$ lymphocytes for gene therapy. Mol Ther 2010;18: 1748-1757.
29. Anliker B, Abel T, Kneissl S, et al. Specific gene transfer to neurons, endothelial cells and hematopoietic progenitors with lentiviral vectors. Nat Methods 2010;7:929-935.

30. Funke S, Maisner A, Mühlebach MD, et al. Targeted cell entry of lentiviral vectors. Mol Ther 2008:16:1427-1436.

31. Zhou 0, Uhlig KM, Muth $A$, et al. Exclusive transduction of human CD4+ $T$ cells upon systemic delivery of CD4-targeted lentiviral vectors. J Immunol 2015;195:2493-2501.

32. Bender RR, Muth A, Schneider IC, et al. Receptortargeted Nipah virus glycoproteins improve cell-type selective gene delivery and reveal a preference for membrane-proximal cell attachment. PLoS Pathog 2016:12:e1005641.

33. Pfeiffer $A$, Thalheimer FB, Hartmann $S$, et al. In vivo generation of human CD19-CAR T cells results in Bcell depletion and signs of cytokine release syndrome. EMBO Mol Med 2018;10:e9158.

34. Kichler A, Leborgne C, März J, et al. Histidine-rich amphipathic peptide antibiotics promote efficient delivery of DNA into mammalian cells. Proc Natl Acad Sci U S A 2003;100:1564-1568.

35. Fenard D, Ingrao D, Seye A, et al. Vectofusin-1, a new viral entry enhancer, strongly promotes lentiviral transduction of human hematopoietic stem cells. Mol Ther Nucleic Acids 2013;2:e90.

36. Majdoul S, Seye AK, Kichler A, et al. Molecular determinants of vectofusin-1 and its derivatives for the enhancement of lentivirally mediated gene transfer into hematopoietic stem/progenitor cells. J Biol Chem 2016;291:2161-2169.

37. Piovan C, Marin V, Scavullo C, et al. Vectofusin-1 promotes RD114-TR-pseudotyped lentiviral vector transduction of human HSPCs and T lymphocytes. Mol Ther Methods Clin Dev 2017:5:22-30.

38. Ingrao D, Majdoul S, Seye AK, et al. Concurrent measures of fusion and transduction efficiency of primary CD34+ cells with human immunodeficiency virus 1-based lentiviral vectors reveal different effects of transduction enhancers. Hum Gene Ther Methods 2014;25:48-56.

39. Vermeer LS, Hamon L, Schirer A, et al. Vectofusin1 , a potent peptidic enhancer of viral gene transfer forms $\mathrm{pH}$-dependent a -helical nanofibrils, concentrating viral particles. Acta Biomater 2017;64: 259-268.

40. Jamali A, Kapitza L, Schaser T, et al. Highly efficient and selective CAR-gene transfer using CD4- and CD8-targeted lentiviral vectors. Mol Ther Methods Clin Dev 2019;13:371-379.

41. Merten O-W, Charrier S, Laroudie N, et al. Largescale manufacture and characterization of a lentiviral vector produced for clinical ex vivo gene therapy application. Hum Gene Ther 2011;22:343-356.

42. Moll M, Klenk H-D, Maisner A. Importance of the cytoplasmic tails of the measles virus glycopro- 
teins for fusogenic activity and the generation of recombinant measles viruses. J Virol 2002;76: 7174-7186.

43. Lock D, Mockel-Tenbrinck N, Drechsel K, et al. Automated manufacturing of potent CD20directed chimeric antigen receptor $T$ cells for clinical use. Hum Gene Ther 2017;28:914-925.

44. Charrier S, Ferrand M, Zerbato M, et al. Quantification of lentiviral vector copy numbers in individual hematopoietic colony-forming cells shows vector dose-dependent effects on the frequency and level of transduction. Gene Ther 2011;18:479-487.

45. Scaramuzza S, Biasco L, Ripamonti A, et al. Preclinical safety and efficacy of human $\mathrm{CD} 34^{+}$cells transduced with lentiviral vector for the treatment of wiskott-aldrich syndrome. Mol Ther 2013;21: 175-184.

46. Verhoeyen E, Costa C, Cosset F-L. Lentiviral vector gene transfer into human T cells. Methods Mol Biol 2009;506:97-114.

47. Bernadin 0, Amirache F, Girard-Gagnepain A, et al. Baboon envelope LVs efficiently transduced human adult, fetal, and progenitor $T$ cells and corrected SCID-X1 T-cell deficiency. Blood Adv 2019;3:461-475.

48. Johannsdottir HK, Mancini R, Kartenbeck J, et al. Host cell factors and functions involved in vesicular stomatitis virus entry. J Virol 2009;83:440-453.

49. Navaratnarajah CK, Leonard VHJ, Cattaneo R. Measles virus glycoprotein complex assembly, receptor attachment, and cell entry BT-measles: history and basic biology. In: Griffin DE, Oldstone MBA, eds. Berlin, Heidelberg: Springer Berlin Heidelberg, 2009: pp. 59-76.

50. Ghani K, Cottin S, Kamen A, et al. Generation of a high-titer packaging cell line for the production of retroviral vectors in suspension and serum-free media. Gene Ther 2007;14:1705-1711.

51. Swift S, Lorens J, Achacoso P, et al. Rapid production of retroviruses for efficient gene delivery to mammalian cells using 293T cell-based systems. Curr Protoc Immunol 2001;Chapter 10:Unit 10.17C.
52. Locke FL, Ghobadi A, Jacobson CA, et al. Longterm safety and activity of axicabtagene ciloleucel in refractory large B-cell lymphoma (ZUMA-1): a single-arm, multicentre, phase 1-2 trial. Lancet Oncol 2019;20:31-42.

53. Maude SL, Laetsch TW, Buechner J, et al. Tisagenlecleucel in children and young adults with Bcell lymphoblastic leukemia. N Engl J Med 2018; 378:439-448.

54. Schuster SJ, Bishop MR, Tam CS, et al. Tisagenlecleucel in adult relapsed or refractory diffuse large B-cell lymphoma. N Engl J Med 2019;380: 45-56.

55. Jung I-Y, Lee J. Unleashing the therapeutic potential of CAR-T cell therapy using gene-editing technologies. Mol Cells 2018;41:717-723.

56. Aiuti A, Cattaneo F, Galimberti S, et al. Gene therapy for immunodeficiency due to adenosine deaminase deficiency. N Engl J Med 2009;360: 447-458.

57. Zhao Y, Wang OJ, Yang S, et al. A herceptinbased chimeric antigen receptor with modified signaling domains leads to enhanced survival of transduced T lymphocytes and antitumor activity. J Immunol 2009;183:5563-5574.

58. Biffi A, Montini E, Lorioli L, et al. Lentiviral hematopoietic stem cell gene therapy benefits metachromatic leukodystrophy. Science 2013;341: 1233158.

59. Gaspar HB, Cooray S, Gilmour KC, et al. Hematopoietic stem cell gene therapy for adenosine deaminase-deficient severe combined immunodeficiency leads to long-term immunological recovery and metabolic correction. Sci Transl Med 2011;3:97-80.

60. Río P, Navarro S, Guenechea G, et al. Engraftment and in vivo proliferation advantage of genecorrected mobilized CD34+ cells from Fanconi anemia patients. Blood 2017;130:1535-1542.

61. Amirache F, Levy C, Costa C, et al. Mystery solved: VSV-G-LVs do not allow efficient gene transfer into unstimulated T cells, B cells, and HSCs be- cause they lack the LDL receptor. Blood 2014;123: 1422-1424

62. Frecha C, Costa C, Lévy C, et al. Efficient and stable transduction of resting $\mathrm{B}$ lymphocytes and primary chronic lymphocyte leukemia cells using measles virus gp displaying lentiviral vectors. Blood 2009;114:3173-3180.

63. Finkelshtein D, Werman A, Novick D, et al. LDL receptor and its family members serve as the cellular receptors for vesicular stomatitis virus. Proc Natl Acad Sci U S A 2013;110:7306-7311.

64. Münch RC, Mühlebach MD, Schaser T, et al. DARPins: an efficient targeting domain for lentiviral vectors. Mol Ther 2011;19:686-693.

65. Brindley MA, Takeda M, Plattet P, et al. Triggering the measles virus membrane fusion machinery. Proc Natl Acad Sci U S A 2012;109:E3018-E3027.

66. Kochenderfer JN, Dudley ME, Feldman SA, et al. B-cell depletion and remissions of malignancy along with cytokine-associated toxicity in a clinical trial of anti-CD19 chimeric-antigen-receptortransduced T cells. Blood 2012;119:2709-2720.

67. Yang S, Rosenberg SA, Morgan RA. Clinical-scale lentiviral vector transduction of PBL for TCR gene therapy and potential for expression in lessdifferentiated cells. J Immunother 2008;31:830-839.

68. Morgan RA, Yang JC, Kitano M, et al. Case report of a serious adverse event following the administration of $T$ cells transduced with a chimeric antigen receptor recognizing ERBB2. Mol Ther 2010;18:843-851.

69. Hartmann J, Schüßler-Lenz M, Bondanza A, et al. Clinical development of CAR T cells-challenges and opportunities in translating innovative treatment concepts. EMBO Mol Med 2017;9:11831197.

Received for publication July 4, 2019; accepted after revision September 21, 2019.

Published online: October 1, 2019. 